$\mathcal{G S}_{\text {https://doi.org/10.3765/sp.9.15 }}^{\text {Semantics \& Pragmatics Volume 9, Article 15: 1-65, } 2016}$

\title{
Covert distributivity in algebraic event semantics*
}

\author{
Lucas Champollion \\ New York University
}

Submitted 2015-08-08 / First decision 2015-11-26 / Revision received 2016-02-02 / Accepted 2016-02-04 / Final version received 2016-02-10 / Early access 2016-06-03 / Published 2017-06-06

\begin{abstract}
This is the first in a pair of papers that aim to provide a comprehensive analysis of the semantic phenomenon of distributivity in natural language. This paper investigates and formalizes different sources of covert distributivity. Apart from lexical distributivity effects, which are modeled by meaning postulates, phrasal distributivity is captured via two covert operators: (i) a D operator distributing over atoms only (Link 1987), and (ii) a cover-based Part operator, which can also distribute over nonatomic pluralities under contextual licensing (Schwarzschild 1996). The resulting theory surpasses accounts in which nonatomic distributivity is freely available, or not available at all; furthermore, it correctly predicts differences between lexical and phrasal nonatomic distributivity. D and Part are reformulated in Neo-Davidsonian algebraic event semantics, so that they apply to event predicates and make the sum event available for further modification by arguments and adjuncts. This paves the way for an account of the context-dependency of distributivity phenomena under for-adverbials, which improves on theories that predict indefinites to either always or never covary with for-adverbials. The paper and its companion include an explicit proposal for the compositional process in event semantics.
\end{abstract}

Keywords: distributivity, algebraic semantics, covers, leakage, for-adverbials

* For discussions and comments, I thank Chris Barker, Justin Bledin, Benjamin Bruening, Seth Cable, Chris Collins, Zsófia Gyarmathy, Robert Henderson, Chris LaTerza, Roger Schwarzschild, Anna Szabolcsi, Linmin Zhang, and audiences at the University of Potsdam, at my 2013 and 2014 NYU seminars, and at my 2015 LSA summer institute course. For native speaker judgments, I thank Renée Blake, Chris Collins, Stephanie Harves, Mike Kennedy, and Todd Snider. This paper builds on earlier work for which I am indebted to many people and institutions as indicated there (Champollion 2010b, 2012, 2013). I thank Todd Snider for proofreading and copyediting the paper. Special thanks to the S\&P editor, Kjell Johan Sæbø, to Malte Zimmermann, and to the reviewers.

(C)2016 Lucas Champollion

This is an open-access article distributed under the terms of a Creative Commons Attribution License (https://creativecommons.org/licenses/by/3.o/). 
Lucas Champollion

\section{Introduction}

This paper presents a theory of covert distributivity that focuses on the distinction between lexical and phrasal distributivity and advocates a middle road in the debate on whether distributivity is atomic or nonatomic. I suggest a reformulation of the classical definition of distributivity operators and propose to expand their use into the temporal domain. This is one of two selfcontained papers that can be read individually but that form a coherent whole. The purpose of these papers is to bring together several strands of research on semantic and pragmatic phenomena in order to provide a comprehensive analysis of distributivity in natural language. This paper focuses on covert distributivity. Its counterpart focuses on overt distributivity; I will refer to it as Champollion 2016.

Covert distributivity as I will talk about it in this paper is diagnosed by the ability of indefinites or numerals in object position to covary in a way that is generally attributed to a covert verb-phrase-level modifier called the D operator (Link 1987, Roberts 1987). The meaning of this kind of operator is either similar to the adverbial modifier each or it corresponds to something like each salient part of, where salience is a context-dependent notion (Schwarzschild 1996). For an overview of the major empirical phenomena related to distributivity, see also Champollion to appear: §2.

The ambiguity between distributive and scopeless readings in English can be modeled by assuming that the D operator is optionally present as a silent verb phrase modifier whose syntax and meaning correspond to that of adverbial each. For example, (1a) represents a scopeless reading and (1b) a distributive reading. I use the term scopeless to refer both to collective and cumulative readings. The distinction between these two readings does not matter for this paper. See Landman 2000 for discussion.
a. The boys saw two monkeys.
$\approx$ The boys between them saw two monkeys.
scopeless
b. The boys [D [saw two monkeys]].
$\approx$ The boys each saw two monkeys.
distributive

This paper makes both technical and empirical contributions to semantic theory. The main technical contribution of this paper is a reformulation of distributivity operators that makes them compatible with Neo-Davidsonian algebraic event semantics (Davidson 1967, Parsons 1990, Krifka 1989a, 1998). This reformulation makes it possible to draw on the resources of event 
semantics in order to formally model the relations between distributivity over individuals and over events and times in a parallel way. Moreover, it makes it possible to draw on the resources of algebraic semantics and mereology in order to formally model the relations between distributivity over atoms and over nonatomic entities like time intervals in a parallel way.

The main empirical contribution of this paper is a unified theory of covert atomic and nonatomic distributivity, over individuals and over temporal intervals, at the lexical and at the phrasal level. Nominal and temporal distributivity have not previously been related. Here I understand distributivity as involving the application of a predicate to the members or subsets of a set, or to the parts of an entity (individual, event, or interval). This application is diagnosed by the presence of what I call distributive entailments. An example of distributivity in the nominal domain was already given in (1b); here is another one:

(2) The girls are wearing a black dress.

(Winter 2001)

This example involves distributivity because on its most plausible interpretation it entails that each of the girls in question wears a (different) black dress. Thus the predicate wear a black dress is applied to the members or parts of the set or collective denoted by the girls. The fact that the predicate includes an indefinite, a black dress, makes it especially easy to diagnose the presence of distributivity, since in the absence of a universal quantifier, a distributivity operator needs to be postulated in order to explain why this indefinite can covary, that is, can be interpreted as involving reference to more than one dress in total.

At this point, two caveats need to be made. First, distributive readings with definite plurals taking scope over singular indefinites are somewhat marked and not always easily available (Dotlačil 2010, Champollion to appear). Second, to the extent that we admit strange models in which several girls can wear the same dress, for example if the dress is very large, the predicate wear a black dress does not have to be interpreted distributively. I will set these two points aside in the following discussion.

There has been a longstanding debate about whether and to what extent distributivity over nonatomic entities, or "genuine plural quantification" (Link 1987), ever occurs (Link 1987, Gillon 1987, 1990, Lasersohn 1989, Schwarzschild 1996, Winter 2001, Kratzer 2007). Here is a preview of the argument developed in Schwarzschild 1996. Schwarzschild argues that the distributivity operator should be modified to allow for nonatomic interpretations in 
a limited set of circumstances, essentially whenever there is a particularly salient way to divide a plural individual into parts other than its atoms. Here is an example. Shoes typically come in pairs, so a sentence like (3) can be interpreted as saying that each pair of shoes costs fifty dollars, as opposed to each shoe or all the shoes together.

\section{(3) Context: 3 pairs of shoes are on display, each pair with a \$50 tag} The shoes cost fifty dollars.

(Lasersohn 1998)

Since the numeral fifty dollars covaries with pairs of shoes rather than with shoes, this example is generally taken to involve nonatomic distributivity. The presence of this kind of interpretation depends on contextual factors. For example, it is not part of the meaning of sentence (3) itself that shoes typically come in pairs. Verb phrases can only be interpreted as distributing over nonatomic entities if there is supporting context or world knowledge that makes these nonatomic entities pragmatically salient. In the absence of this support, verb phrases must distribute over atoms or not at all, as the following example shows.

(4) John, Mary, Bill, and Sue were paid fifty dollars.

(based on Lasersohn 1989)

This example can be interpreted as saying that the four people in question were each paid fifty dollars, or that they were paid fifty dollars together. Out of the blue, nonatomic interpretations are not available. For example, in a scenario where each of the four people in question was paid twenty-five dollars, the sentence is false, even though there are ways to group the four people into pairs such that each pair was paid a total of fifty dollars.

Schwarzschild (1996) suggests that the difference between (3) and (4) is due to the lack of a contextually salient partition or cover in the latter case. He models this by making the distributivity operator anaphoric on such a cover, and renaming it the Part operator. In this paper, I adopt this strategy and extend it to the temporal domain, to create a parallel between the discussion of nominal and temporal nonatomic distributivity. The parallel can be illustrated by the following pair of examples:

(5) a. John found a flea for ten minutes / for a month.

b. The patient took two pills for a month and then went back to one pill. 
The ten-minute variant of (5a) is from Zucchi \& White 2001, while (5b) is based on observations in Moltmann 1991. Out of the blue, examples like these two are odd, and seem to suggest that the same flea is found repeatedly and the same pills are taken repeatedly. Thus, Zucchi \& White give their example two question marks, and describe it as not acceptable unless understood iteratively. Iterative interpretations can improve such examples, but they require special contexts. At least in the case of $(5 b)$, it is easy to find such a context. For example, (5b) is acceptable in a hospital context where the patient's daily intake is salient. It does not require any pill to be taken more than once. In the case of (5a), finding such a context is harder, particularly for the ten-minute variant.

I will argue that this diagnoses verb-phrase-level distributivity, and that it is caused by the presence of a temporal analogue of the Part operator discussed above. The contribution of this operator in example (5b) can be paraphrased as every day. The operator takes scope over the verb phrase take two pills but under the for-adverbial. The month-long interval introduced by the for-adverbial plays the same role vis-à-vis the distributivity operator as the collective individual denoted by the shoes does in example (3).

I will contrast this theory with an alternative view, on which the covariation in (5b) is due to the for-adverbial itself, and no distributivity operator is present in examples like it. On that alternative view, the for-adverbial is interpreted as a universal quantifier meaning something like at each relevant point during a month, as has been suggested at various times in the literature (Dowty 1979, Moltmann 1991, Deo \& Piñango 2011). I will argue that for-adverbials cannot be interpreted as universal quantifiers, since out of the blue they do not induce covariation in indefinites they outscope - see (5a) - except when an overt distributive quantifier intervenes. This is shown in example (6), adapted from Zucchi \& White 2001, where a multiple-fleas interpretation is readily available:

(6) John found a flea on his dog every day for a month.

In examples where the "same-object" and "different-objects" interpretations are both plausible, a similar contrast can be observed. In (7a), one golf ball must have been hit and retrieved repeatedly, while in ( $7 \mathrm{~b})$ it is also possible that each time a different ball was hit (Zucchi p.c. to van Geenhoven 2005):

(7) a. Jim hit a golf ball into the lake for an hour.

b. Jim hit a golf ball into the lake every five minutes for an hour. 
I will account for the contrast between (5a) and (6), and analogously for the contrast between ( $7 \mathrm{a})$ and ( $7 \mathrm{~b})$, by claiming that the temporal distributivity operator cannot occur in the former, and that every day or every five minutes plays its role in the latter. This requires an explanation of why the operator is not able to occur in (5a) or (7a) out of the blue. I will suggest that its (in)ability to occur is due to a contextual factor: it is anaphoric on a salient set of stretches of spacetime, in the same way as the nonatomic distributivity operator in (3) is anaphoric on a salient set of shoes.

While the topic of this paper is covert distributivity, the topic of Champollion 2016 is overt distributivity, as manifested in adverbial each and its adnominal and determiner counterparts both in English and other languages (Zimmermann 2002). The meanings of these items varies in ways that sometimes require them to distribute over individuals (such as in the case of each) and in other cases allow them to distribute over salient parts of spacetime (such as in the case of German jeweils). The main claim of Champollion 2016 is that the D operator relates to the Part operator in the same way as each relates to jeweils. Thus, overt and covert distributivity share many similarities. This gives rise to similar questions in the two cases. Can a distributivity operator only distribute down to singular entities or also to plural entities? Do these entities need to be of a certain size or "granularity", and can this size vary from operator to operator? Must these entities have been overtly mentioned in the sentence and thereby contributed by semantic means, or can they also be supplied by the context via pragmatic means?

A unified semantic analysis of distributivity should make it apparent which aspects of the meanings of various distributivity operators are always the same, and along which dimensions these meanings can differ. I will explain the fact that the various overt and covert distributivity operators share some part of their meanings. To do so, I will view distributivity as the property of a predicate which, whenever it holds of a certain entity or event, also holds of its parts along a certain dimension and down to a certain granularity. I have previously developed and defended this view at length under the name of strata theory (Champollion 2010b, 2015a,b, 2017). Going beyond distributivity, strata theory has applications in the domains of aspect and measurement. Here, I focus on distributivity. Strata theory conceptualizes dimension and granularity as parameters which can be set to different values for different instances of distributivity. The dimension parameter takes a (partial) function as its value. It specifies the domain in which the predicate in question is distributed. For the purpose of this paper, different settings of 
this parameter will allow us to capture the commonalities and differences between distributivity over discrete (count) domains and distributivity over domains involving continuous dimensions, such as time and mass domains. The granularity parameter takes a predicate as its value. It is used to specify that the parts in question must be atomic, or that they can be nonatomic but must be very small as measured along the specified dimension. This parameter accounts for the differences between distributive constructions over discrete and continuous domains. The two parameters interact with each other against the background of assumptions about the metaphysics of natural language. For example, I assume that time is nonatomic, or in any case that it does not make its atoms available to the semantics of natural language. As a result, when the dimension parameter is set to time, the granularity parameter cannot be set to Atom, because time does not provide any atoms to distribute over.

As will become clear, this understanding of distributivity provides several theoretical advantages. First, by understanding distributivity as parametrized for granularity, we gain a new perspective on the debate between proponents of atomic and cover-based formulations of distributivity operators. The atomic distributivity operator of Link 1987, Roberts 1987, and Winter 2001 corresponds to one setting of the granularity parameter, and the nonatomic distributivity operator of Schwarzschild 1996 corresponds to another setting. Following Schwarzschild, I will assume that there is a distributivity operator whose granularity parameter is anaphoric on its context and can only be set to a nonatomic value when context supports a salient granularity level.

Second, by understanding distributivity as parametrized for dimension, we gain the technical ability to distinguish agent-based from theme-based distributivity and the like (Lasersohn 1998). Indeed, not only thematic roles like agent and theme can be considered dimensions, but also trace functions like runtime and location. We can therefore instantiate the dimension parameter of distributivity with time, or more specifically, with the temporal trace function $\tau$ that maps events to their runtimes (Krifka 1998). Given the assumption that time and space are nonatomic, we expect that this should only be possible when the granularity parameter of the distributivity operator is set to a nonatomic value, which in turn should require context to provide a salient granularity. I will argue that such contexts indeed exist, although they are rare. One example is the hospital context in which (5b) was to be understood. I show that the corresponding phenomenon has already been noticed in the literature on aspect. Through parametrized distributivity, the 
asymmetry between the atomic domain of individuals and the nonatomic domain of time allows us to explain the scopal behavior of for-adverbials. If the distributivity operator is easily available only when its granularity is atomic, then it is expected not to be easily available in the temporal domain of for-adverbials.

The Neo-Davidsonian event-semantic setting also gives us the ability to think of overt and covert distributivity operators as being (co)indexable with different thematic roles. This allows us to capture through a simple change in indexation the kinds of configurations that have otherwise been taken to require type-shifting-based reformulations of the D operator (Lasersohn 1998):

a. The first-year students [D [took an exam]].

Target: agent

b. John [D [gave a pumpkin pie]] to two girls.

Target: goal

As I discuss in Champollion 2016, this phenomenon has a direct counterpart in examples like (9) and (10), which involve adnominal each (Zimmermann 2002, Blaheta 2003):

(9) The boys told the girls two stories each. (two stories per boy)

Target: agent

(10) The boys told the girls two stories each. (two stories per girl)

Target: goal

The theoretical picture that is developed here provides a way to formalize such parallels across instances of distributivity in natural language. Individual items can be analyzed as being hardwired for certain parameter values, so that, for example, the difference between Link's and Schwarzschild's operators, as well as that between each and jeweils, can be described in terms of whether the value of the granularity parameter is prespecified to Atom or can be filled in by context. In this way, overt and covert instances of distributivity fit together and into distributivity theory more generally.

The rest of this paper is organized as follows. In Section 2, I review the literature on covert distributivity in the nominal domain, focusing on the atomic distributivity operator introduced in Link 1987 and Roberts 1987. Nonatomic distributivity is discussed in Section 3, where I present the nonatomic distributivity operator introduced in Schwarzschild 1996, summarize the literature on the topic, and describe my own view. The question of how to adapt distributivity operators into event semantic frameworks, such as 
the one adopted here, is discussed in Section 4. In that section, I argue for a specific way to do so, which I argue in Section 5 to be superior to a previous proposal by Lasersohn (1998). I outfit the D and Part operators with dimension and granularity parameters. When the dimension parameter of the reformulated Part operator is set to time, the result induces covariation of indefinites over salient stretches of time. Section 6 builds on this result and provides an account of the limited ability of covariation by indefinites in the scope of for-adverbials. Section 7 summarizes and concludes.

\section{Atomic distributivity}

Let me now present the theory of atomic distributivity initiated by Link (1987) and Roberts (1987), and further developed by subsequent authors. I start here with the atomic distributivity operator $\mathrm{D}$ as originally defined by Link and Roberts, and the motivation that led to it. In the next section, I focus on the nonatomic distributivity operator Part as originally defined by Schwarzschild (1996). The discussion here takes inspiration from Winter 2001, Chapter 6, which in turn builds on Link 1987, Roberts 1987, and others. For other introductions to the same topic, see also Schwarzschild 1996, Chapter 6; Link 1997, Section 7.4; and Champollion to appear, Section 2.

Distributivity can be understood, among other things, as a property of predicates, in opposition to collectivity. Certain lexical predicates (that is, predicates that consist of just one word) such as smile, and certain phrasal predicates (that is, predicates that consist of several words, typically a verb and an object) such as wear a black dress, are distributive: whenever several people smile or wear a black dress, this entails that each of them smiles or wears a black dress. The distinction between lexical and phrasal predicates that have distributive interpretations will be important throughout this paper. To highlight this distinction, from now on I will speak of lexical distributivity when there is a single word that is understood distributively, and I will speak of phrasal distributivity when a phrase that consists of more than one word is understood distributively. As the following examples show, we find distributive and collective interpretations in both classes of predicates:

(11) Lexical distributivity/collectivity

a. The children smiled.

b. The children were numerous.

distributive

collective

\section{Phrasal distributivity/collectivity}


Lucas Champollion

a. The girls are wearing a black dress.

distributive

b. The girls are sharing a pizza.

collective

Distributivity and collectivity can be given operational definitions in terms of entailments or lack thereof; for details, see Champollion 2010b and Champollion to appear. Sentence (11a) entails that each child smiled, while sentence (11b) does not entail that each child was numerous. Similarly, sentence (12a) entails that each girl wears a different dress, but sentence (12b) does not entail that the girls ate different pizzas.

The distinction between lexical and phrasal distributivity is similar to the P/Q-distributivity distinction introduced in Winter 1997, 2001. Winter uses the term $P$-distributivity (where $P$ stands for predicate) to refer to those cases of distributivity which can, in principle, be derived from some property of the verb involved. $Q$-distributivity ( $Q$ for quantificational) refers to cases where this approach is not possible because the distributive predicate contains an indefinite or numeral quantifier, as in (12a). In order for (12a) to entail that each girl wears a different dress, the entire verb phrase, including its object, must be distributed over the girls. This means that the entire verb phrase wear a black dress and not just the verb wear must be regarded as distributive. In this verb phrase, the quantifier is introduced by a separate word, so this is a case of phrasal distributivity. The difference between lexical and phrasal distributivity corresponds to the difference between what can and what cannot be ascribed to the lexical semantics of the verb. It is possible to ascribe the difference between (11a) and (11b) to the meaning of smile and be numerous. The difference between the distributive interpretation in (12a) and the collective interpretation in (12b) is of a different kind, since it involves a scopal ambiguity. Accounts that are based only on lexical semantics cannot model Q-distributivity, and therefore cannot model phrasal distributivity, because they cannot create a scopal dependency between the definite subject and the indefinite object. For more details, see Winter 2001: §3.2, 6.1.

The standard account of distributivity, which I will adopt here too, is based on classical extensional mereology. For an overview of the axioms and linguistic applications of mereology, see Champollion \& Krifka 2016. Briefly, we assume that the domain of individuals is ordered by a parthood relation $\leq$, which is assumed to be a partial order. (Other domains such as events and temporal intervals that will be introduced later are assumed to come with their own analogous parthood relations.) Abbreviating $\exists z[z \leq x \wedge z \leq y]$ as $x \circ y$ (“ $x$ overlaps $y$ ”), we can now define the notion of sum, intuitively 
Covert distributivity in algebraic event semantics

as that which you get when you fuse together a collection of entities (Tarski 1935):

$$
\begin{aligned}
& x=\bigoplus P \\
& \stackrel{\text { def }}{=} \forall y[P(y) \rightarrow y \leq x] \wedge \forall z\left[z \leq x \rightarrow \exists z^{\prime}\left[P\left(z^{\prime}\right) \wedge z \circ z^{\prime}\right]\right]
\end{aligned}
$$

(An entity $x$ is the sum of a set of entities $P$ if and only if everything in $P$ is a part of $x$ and every part of $x$ overlaps with something in $P$.)

Given that $\leq$ is a partial order, sums can be shown to be least upper bounds with respect to $\leq$ (Tarski 1935, Hovda 2009). I have written $\bigoplus P$ for the mereological sum of all entities to which $P$ applies; some authors write $\sigma$ instead of $\oplus$. We can see $\bigoplus$ as the generalization of a binary operation $x \oplus y$, which corresponds to the case where $P$ applies only to the two entities $x$ and $y$. This operation $\oplus$ can be shown to be associative, commutative and idempotent.

Within the mereological framework, the usual way to model Q-distributivity is to introduce a covert distributive operator in the logical representation so that the indefinite can take scope at two different places with respect to it. This is the purpose of the D operator postulated by Link (1987) and Roberts (1987). It shifts a verb phrase to a distributive interpretation, more specifically, one that holds of any individual whose atomic parts each satisfy the unshifted verb phrase. (The operator goes back to Link 1991, which was written before Link 1987. See Roberts 1987: 157 for discussion.) This D operator is usually defined as follows.

\section{Link's D operator}

$\llbracket \mathrm{D} \rrbracket=\lambda P \lambda x \forall y[y \leq x \wedge \operatorname{Atom}(y) \rightarrow P(y)]$

(Takes a predicate $P$ over individuals and returns a predicate that applies to any individual whose atomic parts each satisfy $P$.)

Here, the variable $x$ is resolved to a plural entity, typically provided by the subject, and $y$ ranges over its atomic parts, that is, those parts of $x$ which have only themselves as parts. These atomic parts intuitively stand for the singular individuals of which $x$ consists. The operator introduces a universal quantifier, and it is the scopal interaction of this quantifier with the indefinite inside a Q-distributive predicate that accounts for the covariation effects. For example, if the verb phrase wear a black dress is represented as $\lambda x \exists z[\operatorname{black}(z) \wedge \operatorname{dress}(z) \wedge$ wear $(x, z)]$, the meaning of (12a) can be represented in a way that places it in the scope of the universal 
quantifier introduced by the D operator. Here and below, I write $\bigoplus$ girl for the sum of all girls, the plural individual that corresponds to the girls.

$$
\begin{aligned}
& \forall y\left[y \leq_{\text {Atom }} \oplus \operatorname{girl} \rightarrow \exists z[\operatorname{black}(z) \wedge \operatorname{dress}(z) \wedge \text { wear }(y, z)]\right] \\
& \text { (Every atomic part of the sum of all girls wears a black dress.) }
\end{aligned}
$$

The D operator is able to apply to entire verb phrases and not just to lexical predicates. It is this property that allows it to account for phrasal distributivity (Dowty 1987, Roberts 1987, Lasersohn 1995). Moreover, at least Roberts 1987 allows the D operator to apply to any predicate, whether it is a verb phrase or not. For example, it may apply to a predicate that has been derived by $\lambda$-abstraction over a nonsubject predicate in order to derive an interpretation of (16) where each of two girls received a pumpkin pie:

(16) John gave a pumpkin pie to two girls.

(two girls) $\mathrm{D}[\lambda x$. John gave a pumpkin pie to $x] \quad$ (Roberts 1987)

This approach involves an otherwise unmotivated structure or perhaps an application of quantifier raising, and is criticized for this reason by Lasersohn (1998), whose own proposal is the topic of Section 5 in this paper. The need for the D operator to be able to target noun phrases other than the subject is an important point, and I return to it in Section 4. As we will see, my own implementation deals with nonsubject predicates by parameterizing the $\mathrm{D}$ operator for different thematic roles. But first, I turn to a review of nonatomic distributivity.

\section{Nonatomic distributivity}

In Section 2, I presented the atomic view on distributivity. This view assumes that phrasal distributivity involves universal quantification over atomic parts of the plural individual, that is, over singular individuals. On this view, the distributive reading of a sentence like The girls are wearing a black dress is equivalent to The girls are each wearing a black dress. The indefinite a black dress covaries with respect to a covert universal quantifier that ranges over individual girls. This view is defended in Lasersohn 1995, 1998, Link 1997, and Winter 2001, among others. By contrast, the nonatomic view holds that phrasal distributivity involves universal quantification over certain parts of the plural individual, and that these parts can be nonatomic. Variants of this view are defended in Gillon 1987, 1990, Verkuyl \& van der Does 1991, van der 
Does \& Verkuyl 1996, Schwarzschild 1996: Chapter 5, Brisson 1998, 2003, and Malamud 2006a,b. This section presents and motivates the nonatomic view.

Section 1 mentioned examples like (3) (The shoes cost fifty dollars), where context can make nonatomic interpretations available. This kind of example is discussed in Schwarzschild 1996. There, Link's distributivity operator is modified so that it is no longer restricted to distribute over atoms. The nonatomic view is based on sentences like the following, which is adapted from Gillon 1987:

(17) Rodgers, Hammerstein, and Hart wrote musicals.

This sentence plays on a particular fact of American culture: neither did the three composers it mentions ever write any musical together, nor did any of them ever write one all by himself. However, Rodgers and Hammerstein wrote the musical Oklahoma! together, and Rodgers and Hart wrote the musical On Your Toes together. On the basis of these facts, the sentence is judged true in the actual world, although it is neither true on the collective interpretation (since no musical was written by the three composers together) nor on an "atomically distributive" interpretation (since it is not true that each of them wrote any musical by himself).

An early argument for the nonatomic view was given as follows (Gillon 1987, 1990): in order to generate the reading on which (17) is true, the predicate wrote musicals must be interpreted as applying to nonatomic parts of the sum individual to which the subject refers. This view is generally implemented with the concept of a cover. In a set-based representation of plural individuals, covers are like partitions of a set except that their cells can overlap. Formally, a set $C$ is a cover of a set $S$ if and only if $C$ is a set of nonempty subsets of $S$ whose union is $S$. Translated to a mereological setting, a set $C$ is a cover of a plural entity $x$ if and only if $C$ is a set of parts of $x$ whose sum is $x$.

Cover-based approaches modify the distributivity operator by relaxing the "atomic part" condition and by quantifying over nonatomic parts of a cover of the plural individual (Schwarzschild 1996). The first cover-based approaches assumed that the cover can be existentially quantified by the operator that introduces it. In an eventless setting, this assumption can be implemented by a distributivity operator such as (18). On this view, the denotation of sentence (17) can be represented as (19). This formula is verified in the actual world by the existence of the cover \{rodgers $\oplus$ hammerstein, rodgers $\oplus$ hart\}. The 
condition $y \leq x$ in (18) is redundant given that $C$ is required to be a cover of $x$; it is included only for clarity.

Nonatomic distributivity operator, existentially bound cover $\llbracket \mathrm{D}_{\exists} \rrbracket=\lambda P \lambda x \exists C[\operatorname{Cov}(C, x) \wedge \forall y[C(y) \wedge y \leq x \rightarrow P(y)]]$

$\exists C[\operatorname{Cov}(C$, rodgers $\oplus$ hammerstein $\oplus$ hart $) \wedge$

$$
\forall y[\mathrm{C}(y) \wedge y \leq x \rightarrow y \in \llbracket \text { wrote musicals } \rrbracket]]
$$

Existentially bound covers are not a good way to model phrasal distributivity, because they overgenerate readings. These can be described as halfway between collective (or cumulative) and distributive readings, and they are sometimes called intermediate readings. I call them nonatomic readings. For example, suppose that John, Mary, Bill, and Sue are the teaching assistants, that each of them taught a recitation section, and that each of them was paid \$7,0oo last year. Then sentences (20a) and (2ob) are both true (Lasersohn 1989). This is as expected on the atomic approach. Sentence (20a) is true on its distributive reading, and sentence (2ob) is true on its collective or cumulative reading. But sentence (2Oc) is false, even though the cover $\{j \oplus m, b \oplus s\}$ would verify it if it was represented using the $\mathrm{D}_{\exists}$ operator in (18). That is, sentence (20c) does not have a nonatomic reading. (While Lasersohn's scenario involved only three individuals, I have added a fourth, in order to sidestep the question of whether nonatomic readings allow for overlap.)

a. The TAs were paid exactly $\$ 7,000$ last year.

b. The TAs were paid exactly $\$ 28$,ooo last year.

c. The TAs were paid exactly $\$ 14$,ooo last year. distributive collective *nonatomic

Giving up the existential cover-based operator $\mathrm{D}_{\exists}$ in (18) explains why sentence (20c) is false, because without this operator, there is no way to generate a nonatomic reading for this sentence. However, sentence (17) does have a nonatomic reading, so giving up $\mathrm{D}_{\exists}$ requires an alternative account of this reading and the inferences we can draw from it. Here it is important to note that not every inference requires an operator to account for it. For example, the inference from "The TAs have money" to "Each TA has money" does not require a nonatomic distributivity operator because it follows from the assumptions that have is distributive and money has divisive reference (Cheng 1973, Krifka 1989b).

Lasersohn (1989) proposes to account for the nonatomic reading of (17) through the use of lexical meaning postulates like (21): 
Covert distributivity in algebraic event semantics

$\forall x_{1} x_{2} y_{1} y_{2}\left[\left(\operatorname{write}\left(x_{1}, y_{1}\right) \wedge \operatorname{write}\left(x_{2}, y_{2}\right)\right) \rightarrow \operatorname{write}\left(x_{1} \oplus x_{2}, y_{1} \oplus y_{2}\right)\right]$ (Whenever $x_{1}$ writes $y_{1}$ and $x_{2}$ writes $y_{2}, x_{1}$ and $x_{2}$ write $y_{1}$ and $y_{2}$.)

This meaning postulate can be generalized to the assumption that the meanings of all verbs are cumulative, or in other words, closed under (pointwise) sum formation. This is a common and well-motivated assumption in event semantics, at least for Germanic languages (Scha 1981, Schein 1986, 1993, Lasersohn 1989, Krifka 1989b, 1992, Landman 1996, 2000). Following Kratzer 2007, I will refer to this assumption as lexical cumulativity.

Cumulativity is assumed to be a property of all verbs, but not of all verbal constituents. Lexical meaning postulates like (21) differ from distributivity operators in that they are taken to apply only to verbs, and not to verb phrases or larger constituents. Following Kratzer 2007, and contra Sternefeld 1998 and Beck \& Sauerland 2000, I will not generalize the cumulativity assumption from verbs to arbitrary constituents, as this would make it difficult to model the difference between lexical and phrasal distributivity. (In fact, it may even be necessary to prevent cumulativity from freely applying at the level of the verb. This free application amounts to the assumption that iterative interpretations come for free at that level (Kratzer 2007). By various measures, iterative interpretations lead to higher processing costs even at the level of the verb (Deo \& Piñango 2011). If verb-level iterative interpretations are due to lexical cumulativity, these costs are unexpected; for relevant discussion, see Champollion 2013. In this paper, I set aside the question of how to account for higher processing costs of iterative interpretations at the verb level. In Section 6 , I briefly discuss a different kind of processing cost that occurs at the level of the verb phrase.)

Lasersohn's meaning postulate ensures that when a cumulative verb, such as write, combines with a cumulative object, such as musicals, the result is a cumulative verb phrase. Thus when there are two entities - individual people or sums - that each qualify as write musicals, so does their sum. Given what is sometimes called the inclusive view of the plural (which I will adopt), write musicals literally applies to entities who wrote one or more musicals (Krifka 1989b; Sauerland, Anderssen \& Yatsushiro 2005; Spector 2007). Such entities include the sum rodgers $\oplus$ hammerstein and the sum rodgers $\oplus$ hart, and via (21), the sum individual rodgers $\oplus$ hammerstein $\oplus$ hart, of which (21) entails that it wrote the sum individual oklahoma $\oplus$ on.your.toes. This plural individual qualifies as musicals. (Sentence (17) conveys that more than one 
musical in total is written. This can be explained for example by modeling this information as a scalar implicature (Spector 2007, Zweig 2008, 2009).)

Even with the meaning postulate in place, a noncumulative object that combines with a cumulative verb will not generally yield a cumulative verb phrase. Thus, the two sums rodgers $\oplus$ hammerstein and rodgers $\oplus$ hart each satisfy the truth conditions of write a musical, but in the absence of a cover-based distributivity operator, their sum does not. Indeed, the following sentence, unlike (17), is false in the actual world (Link 1997):

(22) Rodgers, Hammerstein, and Hart wrote a musical.

If a cover-based operator like (18) was available in the grammar, that operator would predict (22) to be true in the actual world. Lasersohn and many others conclude from this and similar examples that the atomic approach to phrasal distributivity is superior to covers (e.g., Winter 2001).

However, some sentences do require cover-based operators (Gillon 1990, Schwarzschild 1996). They typically involve special contexts in which a specific cover is salient. This is where the shoe example in (3) comes in, repeated here as (23).

(23) The shoes cost fifty dollars.

(Lasersohn 1998)

This sentence can be interpreted with respect to a cover whose cells each contain a matching pair of shoes. The relevant reading is nonatomic because it asserts that each pair of shoes costs fifty dollars and these pairs are nonatomic parts of the denotation of The shoes. (I assume that pairs of shoes only occur in the denotation of shoes as proper sums, not as atoms, because This is a shoe cannot be uttered to describe a pair of shoes, and because somebody who owns one pair of shoes cannot answer How many shoes do you own? by One.) The reading is not atomically distributive because it does not assert that each shoe costs fifty dollars, and it is not collective because it does not assert that all the shoes taken together cost that much. By contrast, no cover is salient for example (24), and so it can only mean that each suitcase weighs fifty pounds or all of them together do so.

(24) The suitcases weigh fifty pounds.

In the nonatomic reading of (23) above, the quantifier introduced by the object takes scope under the distributivity operator. Unlike the relevant reading of sentence (17), this scopal dependency cannot be captured by a meaning 
postulate like (21). Schwarzschild 1996 models the context dependency of this kind of reading by assuming that the distributivity operator (which he renames Part, to set it apart from Link's D operator) contains a free cover variable whose value is supplied anaphorically by context. I will represent this variable as a subscripted $C$.

(25) Schwarzschild's nonatomic distributivity operator, free cover $\llbracket \operatorname{Part}_{\mathrm{C}} \rrbracket=\lambda P \lambda x \forall y[\mathrm{C}(y) \wedge y \leq x \rightarrow P(y)]$

The difference between D and Part amounts to a division of labor between semantics and pragmatics. Semantics accounts for atomic phrasal distributivity, and pragmatics for nonatomic phrasal distributivity. Schwarzschild assumes that $C$ is restricted through a pragmatic mechanism to be a cover over $x$, but he prefers not to write this condition into his operator.

The introduction of a pragmatic component into the analysis of what had previously been treated as a purely semantic phenomenon is discussed and justified at length in Schwarzschild 1996. Relevant evidence comes from sentences like (26):

(26) The young animals and the old animals were separated.

(Schwarzschild 1996: 44)

This sentence typically entails that the young animals were separated from the old animals but that each of these two groups stayed together. This suggests that the verb phrase be separated is distributed down to the level of these two groups and not all the way down to individual animals. At this point, a proponent of atomic distributivity might argue that the reason that the verb phrase is able to apply at this intermediate level is that the two groups of animals are in fact atoms. The two conjuncts might then be analyzed as involving group-forming operators that map each of the two pluralities of animals to an atom. This route is taken by Landman 1989. Schwarzschild rejects this approach and argues for the essentially pragmatic nature of nonatomic distributivity by pointing out that the inference down to groups is cancellable. The following sentence leaves it open exactly how the animals were separated, a fact that is unexpected on the group-based analysis:

(27) The young animals and the old animals were separated, but not necessarily by age. 
Schwarzschild assumes that the but-clause in (27) prevents the value of $C$ from being set to the cover that is made pragmatically salient by the conjunction. Beyond this kind of case, Schwarzschild does not say much about the precise pragmatic mechanism that resolves $C$. For a proposal in which the Part operator is anaphoric on a decision problem in the sense of van Rooij 2003, see Malamud 2006a,b, 2012. From the present perspective, what matters most in Schwarzschild's and Malamud's approaches is that the Part operator imposes a stronger restriction on the identity of the cover than would be achieved by just existentially quantifying over it. This restriction rules out nonatomic readings in sentences like (20c), (22), and (24), but not in sentences like (23). While I see no obstacles to using decision problems, I will continue to use a Schwarzschild-style approach to keep the representation simple.

Sentence (23) is structurally equivalent to sentences (20c), (22), and (24), yet only (23) has a nonatomic reading. As Heim 1994 and Schwarzschild 1996 argue, this fact provides strong evidence that models of (phrasal) distributivity need to contain a pragmatic factor. The operator in (25) is more restricted than the existential cover-based operator $\mathrm{D}_{\exists}$ in (18) because (25) presupposes the existence of a context through which the variable $C$ can be resolved. The contrast between (23), which has a nonatomic reading, and (20c), (22) and (24), which do not, is predicted on the plausible assumption that a salient context is only available for (23).

To summarize the empirical picture presented in this section, nonatomic distributivity is readily available at the level of the verb (lexical level), but at the level of the verb phrase (phrasal level) it only occurs when context supplies a pragmatically salient cover. Atomic distributivity is available both at the lexical level and at the phrasal level. Summarizing the insights of the previous literature, I assume that this pattern is explained as follows (see Tables 1 and 2). The lexical cumulativity assumption, encoded in meaning postulates like (21), accounts for the availability of atomic and nonatomic distributivity at the lexical level. Link's atomic D operator is always available at the level of the verb phrase, except in some cases such as share a pizza, where its application would lead to nonsensical interpretations. Schwarzschild's cover-based Part operator is also available at the level of the verb phrase, but it is only available if context supplies a salient cover. When this cover contains only one atomic individual in every cell, Schwarzschild's Part operator behaves like Link's D operator. 
Covert distributivity in algebraic event semantics

\begin{tabular}{lll}
\hline & Lexical (verb level) & Phrasal (verb-phrase level) \\
\hline atomic & available & available \\
nonatomic & available & only with context
\end{tabular}

Table 1 Distributivity in atomic domains: empirical generalizations

\begin{tabular}{lll}
\hline & Lexical (verb level) & Phrasal (verb-phrase level) \\
\hline atomic & lexical cumulativity & atomic operator \\
nonatomic & lexical cumulativity & cover-based operator
\end{tabular}

Table 2 Distributivity in atomic domains: explanations

Even though the semantic effects of D can be subsumed under the workings of Part, I postulate two covert distributivity operators, D and Part, in the grammar. This might seem redundant, and I keep them apart mainly for reasons of symmetry with the two kinds of overt distributive items that are the topic of the companion paper, Champollion 2016. For present purposes, it would be equally possible to assume that there is only one operator, namely Part, and that the predicate Atom is a salient cover in every situation. Such a view would amount to the following idea: in an atomic domain, the atomic level always provides a salient cover in every context, and this explains the strong preference that speakers have for atomic-level distributivity (see also Rothstein 2010). When the granularity parameter of Part is set to atoms, it behaves equivalently to D. In Champollion 2016, I argue that D and Part are lexicalized as adverbial and adnominal distributivity operators in individual languages. This assumption allows us to capture the distinction between English each and its German relative jeweils. I suggest that the former corresponds to D and the latter corresponds to Part, and I use this assumption to account for the fact that jeweils and its relatives across languages have a wider range of readings than each and its relatives do.

The search for clear cases of nonatomic distributivity has been going on since at least Link 1987. Nonatomic lexical distributivity can be observed in the "musicals" example (17), as Lasersohn showed. It also has been argued to occur in examples like the following:

(28) a. All competing companies have common interests. (Link 1987) 
b. Five thousand people gathered near Amsterdam.

(van der Does 1993)

In example (28a), the predicate have common interests can be applied distributively (that is, it describes several instances of having common interests) to nonatomic entities, because it does not make sense to say of a single company that it has common interests with itself. In example (28b), the predicate gather near Amsterdam can be applied distributively (that is, it describes several gatherings) to nonatomic entities, because a single person cannot gather.

On the other hand, examples that involve phrasal nonatomic distributivity, such as the shoe example (23), are harder to come by. I believe that one of the reasons why it has been so hard to identify clear cases of phrasal nonatomic distributivity is the focus in the literature on predicates that apply in count domains. On the standard assumption that the denotations of count nouns are taken from an atomic domain, phrasal distributivity over atoms is naturally expected to be more salient than nonatomic distributivity in almost all contexts and will obscure the presence of nonatomic readings.

The view that atomic granularity is more salient than nonatomic granularity is already defended in Schwarzschild 1996. It can be understood in terms of the principle of Interpretive Economy proposed in Kennedy 2007, which can in turn be derived from first principles in an evolutionary game-theoretic setting (Potts 2008). The central idea is that whenever possible, speakers will converge on certain focal points because this maximizes successful communication. Interpretive Economy was originally proposed to explain why speakers converge on interpreting scalar items like tall and full as referring to endpoints of a scale whenever such endpoints exist, and resort to contextdependent values only when this is not the case. In count domains, the scale that results from mapping singular and plural individuals to their cardinalities has an endpoint at 1 , the cardinality of singular (atomic) individuals. Interpretive Economy suggests that speakers who use a covert distributivity operator and who need to agree on how to interpret its granularity parameter converge on atomicity as a focal point, except in contexts where another granularity value is salient. This suggests that by looking at noncount domains, we can remove atomic granularity as a potential focal point, so any phrasal distributivity effects we find must be cases of nonatomic distributivity. A reviewer offers the following example from the mass domain as a case in point: 
(29) At the garden party, they sell milk, lemonade and beer. Milk costs one dollar, lemonade costs two dollars, and beer costs four dollars.

Here, the predicates cost one dollar, etc., are distributed to a level that is made pragmatically salient by the context, namely the units in which the beverages are sold - presumably glasses, bottles or cans.

Another nonatomic domain is time. In Section 6, I will identify cases of nonatomic phrasal distributivity involving time. I will look at this domain through the lens of for-adverbials, focusing on their scopal behavior with respect to verb phrases that contain an overt quantifier. In a nonatomic domain, there are necessarily no atomic covers, so the first rows of Tables 1 and 2 are irrelevant here. I will argue that the second row of these tables is mirrored precisely in the temporal domain, as shown in Tables 3 and 4 .

\begin{tabular}{lll}
\hline & Lexical (verb level) & Phrasal (verb-phrase level) \\
\hline atomic & $\mathrm{n} / \mathrm{a}$ & $\mathrm{n} / \mathrm{a}$ \\
nonatomic & available & only with context
\end{tabular}

Table 3 Distributivity in nonatomic domains: empirical generalizations

\begin{tabular}{lll}
\hline & Lexical (verb level) & Phrasal (verb-phrase level) \\
\hline atomic & n/a & n/a \\
nonatomic & lexical cumulativity & cover-based operator
\end{tabular}

Table 4 Distributivity in nonatomic domains: explanations

Remember that I assume that distributivity always involves a dimension and a granularity parameter. That is, the dimension parameter of the distributivity operator involved can be instantiated to $\tau$ (runtime) and, in that case, its granularity parameter is dependent on an anaphorically salient level of granularity. I have suggested that the distributivity operators contain these two parameters. The granularity parameter can be understood as Schwarzschild's cover, but the dimension parameter does not yet figure in the implementations we have seen so far. Therefore, it is necessary at this point to provide a formal implementation of Link's and Schwarzschild's distributivity operators that supports the notion of dimension and granularity parameters. Section 4 provides this implementation. 
Lucas Champollion

\section{Reformulating the D and Part operators}

In their original formulation, the distributivity operators I have discussed so far only distribute over the subject and return a truth value once they have combined with it. But as we have seen above, examples like (8) - repeated here as (30) - show that these operators must be able to target different argument positions, and that they can combine with more than one constituent:
a. The first-year students [D [took an exam]].
b. John [D [gave a pumpkin pie]] to two girls.
Target: agent
Target: goal

Lasersohn 1998 discusses how to generalize these operators in a way that allows them to distribute over different argument positions. But if the previous discussion is on the right track, distributivity does not have to target overt argument positions. It can also target salient temporal intervals that are not denoted by any argument in the sentence. This cannot easily be accommodated on the traditional Montagovian view, unless we add a silent temporal argument to each verb. A simpler and more uniform picture is provided by Neo-Davidsonian event semantics, on which thematic roles like agent and related functions like runtime are reified. On this view, it makes sense to think of the $\mathrm{D}$ and Part operators as being parametrized on these functions.

Once we move to event semantics, the distributivity operators developed and motivated in the last two sections have to be adjusted for a number of reasons. First, Link's and Schwarzschild's formulations of distributivity operators assume that verb phrases denote sets of individuals, while event semantics typically assumes that verb phrases denote sets of events. Second, like other kinds of quantification in event semantics, distributivity over individuals requires a variable that ranges over subevents of some sum event, and this needs to be built into the operators (Taylor 1985, Schein 1993). Third, as we will see, there is a technical flaw with the main existing proposal of how to represent the D operator in event semantics, namely Lasersohn 1998. Specifically, Lasersohn's operator fails to prevent the sum event from containing extraneous material in addition to the subevents over which the $\mathrm{D}$ operator ranges ("leakage", in the terms of Bayer 1997). This problem also applies to the Part operator.

The background assumptions of algebraic event semantics are laid out, for example, in Krifka 1998 and Champollion 201ob. Here I reformulate the $\mathrm{D}$ and Part operators in a way that meets the requirements above. Section 5 
compares it with the proposal by Lasersohn (1998). I use the following typing conventions: $t$ for truth values, $e$ for ordinary objects, $v$ for events, and $i$ for times. I use the symbols $x, y, z, x^{\prime}, y^{\prime}, z^{\prime}$ and so on for variables that range over ordinary objects, and $e, e^{\prime}, e^{\prime \prime}$ for events. I use $P$ for predicates of type $\langle e, t\rangle, V$ for predicates of type $\langle v, t\rangle, \theta$ and $\Theta$ for functions of type $\langle v, e\rangle$. Some variables range over objects of different types; when this is clear from context, I will continue to use the symbols above. For example, the range of $\theta$ will also include runtime, a function from events to intervals. My notion of events is essentially the one of Eckardt 1998, Krifka 1998, and Parsons 1995. In particular, typical events are individual rather than generic, concrete rather than abstract, and located in spacetime. I assume that different lexical predicates such as singing and tooth-brushing denote disjoint sets, that is, they do not apply to the same event, with the possible exception of subtypes of events: a walking event is also a moving event, for example. I assume that certain kinds of event modifiers can provide clues about the identity of events. For example, if I both brush my teeth and sing, but if my singing is loud while my brushing my teeth is not, then the singing is not the same event as the tooth-brushing (Parsons 1990: 157). Not all event modifiers can provide clues about individuation of events. For example, my arriving at my wedding might not be surprising, but my arriving at the wedding late would certainly be; but we would not want to distinguish these as two separate events (Zsófia Gyarmathy, p.c.). Therefore, surprisingly is not a suitable choice for the individuation test. Among the event modifiers that are suitable we find manner adverbs like loudly, carefully, shyly and temporal expressions like from 2pm to $4 \mathrm{pm}$ (Eckardt 1998: Chapters 1 \& 4).

Individuals, events, and times are each partially ordered by a parthood relation $\leq$. Within each of these domains, any nonempty set of entities has a unique sum. This means that these categories include plural entities (Link 1998). The lowercase variables just mentioned range over both singular and plural entities. In the literature on plurals, the distinction between singular and plural entities is often indicated by lowercase and uppercase variables. Since almost all the variables in my representations range over potentially plural entities, I do not follow this convention.

I assume that singular individuals, the entities in the denotation of singular count nouns, are mereological atoms. The notion of mereological part must be distinguished from the intuitive notion of part: the leg of a table is not a mereological part of the table. My assumption is very convenient and widespread in the literature, but there still remains a question about nouns 
like twig, rock, and sequence (Zucchi \& White 2001). The account I am about to give could still be given without this assumption, as long as there is another way to represent the distinguished level of individuation that is associated with singular individuals, since the D operator will have to be restricted to this distinguished level. One way to represent this level is the natural unit function in Krifka 1989a. Individuation criteria for nouns are discussed in Rothstein 2010 and Barker 2010.

I adopt thematic uniqueness, that is, I assume that each event has at most one agent, at most one theme, etc. (Carlson 1984, 1998, Parsons 1990). This is useful when we extend distributivity to nonatomic domains like time and space, because it allows us to rely on the idea that thematic roles can be treated as being the same kinds of things as functions that map events to their locations in spacetime (Champollion 2010b).

I will use the star operator defined in Link 1983. The star operator applied to a predicate $P$ gives us the algebraic closure of $P$, that is, the closure of $P$ under sum:

$$
x \in{ }^{*} P \stackrel{\text { def }}{=} \exists C[x=\bigoplus C \wedge C \neq \varnothing \wedge C \subseteq P]
$$

( $x$ is the sum of all the elements of a nonempty subset of $\mathrm{P}$ )

According to this definition, $x \in{ }^{*} P$ means that $x$ consists of one or more parts such that $P$ holds of each of these parts. That is, either $P$ holds of $x$ or else there is a way to divide $x$ into parts such that $P$ holds of each of them. To take an analogy from geometry, if $x$ is a square, and $P$ is the property of being a triangle, then $P$ does not apply to $x$, but ${ }^{*} P$ does, since any square can be divided into triangles.

The star operator will play a central role in the development to follow. Distributivity is usually seen as involving universal quantification, and as we will see, the original definitions of Link's (14) and Schwarzschild's (25) operators contain quantifiers. My distributivity operators will be built around the star operator instead. As the following equivalence illustrates, the relation between the two is very close.

\section{(32) Theorem:}

$x \in{ }^{*} P \Leftrightarrow \forall z\left[z \leq x \rightarrow \exists z^{\prime}\left[P\left(z^{\prime}\right) \wedge z^{\prime} \leq x \wedge z \circ z^{\prime}\right]\right]$

(x is in the algebraic closure of $P$ if and only if every part of $x$ overlaps with a part of $x$ that is in $P$.) 
Covert distributivity in algebraic event semantics

The proof of (32) follows from the definitions of sum in (13) and of algebraic closure in (31). Given these definitions, the left-hand side of (32) expands to:

$$
\begin{aligned}
\exists C[C \neq \varnothing \wedge C \subseteq P \wedge \forall y[C(y) & \rightarrow y \leq x] \\
& \left.\wedge \forall z\left[z \leq x \rightarrow \exists z^{\prime}\left[C\left(z^{\prime}\right) \wedge z \circ z^{\prime}\right]\right]\right]
\end{aligned}
$$

from which its right-hand side follows directly. For the other direction, we show that $C_{x}=\{z \mid P(z) \wedge z \leq x\}$ is a witness for $C$ in (33). Clearly $C_{x} \subseteq P$ and $\forall y\left[C_{x}(y) \rightarrow y \leq x\right]$. Given the right-hand side of (32), reflexivity of $\leq$ entails $C_{x} \neq \varnothing$ and the definition of $C_{x}$ entails $\forall z\left[z \leq x \rightarrow \exists z^{\prime}\left[C_{x}\left(z^{\prime}\right) \wedge z \circ z^{\prime}\right]\right]$.

In keeping with the Neo-Davidsonian view on event semantics, I assume that verbs and their projections denote sets of events and are therefore of type $\langle v, t\rangle$ (Carlson 1984, Parsons 1990, Krifka 1992). Verbs are related to their arguments and adjuncts by thematic roles such as agent, theme, and runtime, which I write $\tau$. The application of a predicative or referential noun phrase to a verbal projection amounts to intersecting two sets of events. For example, the interpretation of John loves Mary amounts to intersecting the set of events whose agent is John, the set of loving events, and the set of events whose theme is Mary. At the end of the derivation, a sentence mood operator applies. In a declarative sentence, the declarative sentence mood operator typically binds the event variable existentially.

As is customary in event semantics, I will only account for unmodified numerals like three boys. Modified numerals like exactly three boys and at most three boys can also be handled in principle, but they raise additional issues involving event maximality (Krifka 1989a, 1999, Brasoveanu 2013).

There does not seem to be a best practice of how best to implement event semantics and how to combine verbal projections with their arguments. Some authors adopt more traditional versions of event semantics in which verbs denote relations between events and their arguments (Landman 200o, Krifka 1998), or relations between events and their internal arguments (Kratzer 1996, Harley 2012). Let me briefly mention some empirical and theoretical motivations that lead me to adopt Neo-Davidsonian semantics over these approaches. In Neo-Davidsonian event semantics, thematic roles can be treated as of one and the same kind as other event properties that encode their location in space and time. This makes it a natural fit for the parallel treatment of distribution over individuals and distribution over time intervals. Furthermore, Neo-Davidsonian semantics allows us to adopt a uniform semantic architecture that makes it easier to express the theories in this paper and in Champollion 2016. For example, it exposes thematic roles to 
the compositional semantics, as opposed to keeping some or all of them implicit within the lexical entry of the verb. As we will see in Champollion 2016, this makes it easier to access them via indices or function application. It also allows us to give the same type to all verbal projections, which makes it easier for the distributivity operator to apply uniformly to each projection. Moreover, event semantics makes it possible to treat verbal and nominal projections as predicates of the same arity. This is useful from the point of view of algebraic semantics because it allows us to formulate cross-domain generalizations more easily (Champollion 201ob). Finally, it allows us to treat distance-distributive items uniformly no matter if they occur within verbal or within nominal projections (Champollion 2016). That said, it may be possible to reformulate much of the content of this paper and Champollion 2016 in other approaches than Neo-Davidsonian event semantics if one wishes to do so. For a detailed study of what it takes to reformulate Neo-Davidsonian theories in classical Davidsonian and eventless frameworks, see Bayer 1997. It may also be possible to work in a framework that exposes some but not all thematic roles to the compositional process, as for example Kratzer 1996. This would lead one to expect asymmetries between the agent role and other thematic roles. I have argued elsewhere that the asymmetries that Kratzer tries to model correlate with syntactic positions and not with thematic roles (Champollion 2010a). For more discussion of Kratzer's asymmetries, see Williams 2009.

I assume that thematic roles, events, and verbs are each closed under sum formation; this implements lexical cumulativity (Krifka 1989a, Champollion 2010b). I discuss these assumptions in turn. The cumulativity assumption for thematic roles can be stated as follows:

(34) Cumulativity assumption for thematic roles For any thematic role $\theta$ and any subset $E$ of its domain: $\theta(\oplus E)=\oplus(\lambda x \exists e \in E . \theta(e)=x)$

This says that for any subset of the events on which a given thematic role $\theta$ is defined, we can compute the $\theta$ of their sum by summing up their $\theta$ s. A consequence of this assumption is that thematic roles are homomorphisms, or structure-preserving maps, with respect to the $\oplus$ operation (contrary to Kratzer 2003 - for details see Champollion 2010b: 33):

(35) Fact: Thematic roles are sum homomorphisms

For any thematic role $\theta$ : 
Covert distributivity in algebraic event semantics

$\theta\left(e \oplus e^{\prime}\right)=\theta(e) \oplus \theta\left(e^{\prime}\right)$

(The $\theta$ of the sum of two events is the sum of their $\theta \mathrm{s}$.)

What this says is that, for example, if $e$ is a talking event whose agent is John and $e^{\prime}$ is a talking event whose agent is Mary, $e \oplus e^{\prime}$ is an event whose agent is the sum of John and Mary. Thus, $e \oplus e^{\prime}$ has a unique entity as its agent, even though this entity is a proper sum. This sum operation is independent of time, so it may be that $e$ took place two days ago and $e^{\prime}$ is taking place today. Discontinuous events of this kind will play an important role in the account of covert temporal distributivity in Section 6 and in the account of occasion readings of overt distributive items in Champollion 2016.

Turning now to events and verbs, I assume that the sum of any two events is itself an event. For example, let $e_{1}$ be the event in which John $(j)$ lifts a certain box $b$ and $e_{2}$ the event in which Mary $(m)$ lifts a certain table $t$. The sum $e_{1} \oplus e_{2}$ is itself an event. The agent of $e_{1}$ is $j$ and the agent of $e_{2}$ is $m$. Given that thematic roles are sum homomorphisms, the agent of the sum event $e_{1} \oplus e_{2}$ is $j \oplus m$, the sum of their agents. I assume that whenever two events are in the denotation of a verb, then no matter whether they have the same thematic roles or not, and no matter if their runtimes are identical, adjacent, or otherwise, the sum of these two events is also in the denotation of the verb. Lasersohn's meaning postulate (21) is a special case of this assumption. In the current example, the verb lift applies not only to the event $e_{1}$ and to the event $e_{2}$, but also to their sum $e_{1} \oplus e_{2}$. On this view, verbs can be said to have plural denotations, in the sense that their denotation obeys the same equation (36) as plural count nouns on the inclusive view of the plural, represented in (37):

$$
\begin{aligned}
& \llbracket V \rrbracket=* \llbracket V \rrbracket \\
& \llbracket \mathrm{N}_{p l} \rrbracket=* \llbracket \mathrm{N}_{s g} \rrbracket
\end{aligned}
$$

I include the star operator in the typographical representation of verb meanings as a reminder of the lexical cumulativity assumption, following Kratzer 2007. For example, instead of writing $\lambda e[\operatorname{lift}(e)]$ for the meaning of the verb lift, I write $\lambda e\left[{ }^{*} \operatorname{lift}(e)\right]$. Inspired by Landman 2000, I use the same typographical reminder for thematic roles, except in those cases where it is clear that they map events to atoms. For example, I generally write *agent instead of agent, but I write Atom(agent) rather than Atom(*agent). This notation is meant to be reminiscent of a generalization of the star operator to partial functions, which is defined and discussed in Champollion 2010b: 16. 
The lexical cumulativity assumption is motivated by the entailments in (38) and (39) (Krifka 1989a, 1992). Because of the parallelism between (36) and (37), the explanation of these entailments is completely analogous to the explanation of the entailment in (40), which motivated the treatment of plurality in Link 1983.

a. John slept.

b. Mary slept.

c. $\Rightarrow$ John and Mary slept.

(39) a. John lifted box $b$.

b. Mary lifted table $t$.

c. $\Rightarrow$ John and Mary lifted box $b$ and table $t$.

(40) a. John is a boy.

b. Bill is a boy.

c. $\Rightarrow$ John and Bill are boys.

Lexical cumulativity does not entail that all verb phrases are cumulative, only that all verbs and certain verb phrases are. Among cumulative verb phrases we find all those with constant objects (for example, lift box $b$ ) and those with cumulative objects (for example, lift boxes and write musicals). The proof is simple: since lift is a verb, it is cumulative, so any sum of two lifting events $e_{1}$ and $e_{2}$ is a lifting event. Since theme is a sum homomorphism, the theme of that sum event is the sum of the themes of $e_{1}$ and $e_{2}$. Suppose that $e_{1}$ and $e_{2}$ both qualify as lift box $b$. Then the theme of $e_{1} \oplus e_{2}$ is $b \oplus b$, which is equal to $b$ by idempotence. It follows that $e_{1} \oplus e_{2}$ is in the denotation of lift box $b$. Likewise, if the themes of $e_{1}$ and $e_{2}$ are in the denotation of any cumulative noun such as boxes, so is the sum of these themes. The same reasoning shows that write musicals is cumulative. This corresponds to the proposal by Lasersohn (1989).

As an example of a noncumulative verb phrase, the sum of two events in the denotation of the verb phrase be paid exactly $\$ 7,000$ will not, as a general rule, again be in its denotation, because it will usually involve $\$ 14$,ooo rather than $\$ 7,000$. Likewise, the sum of two events in the denotation of the verb phrase find a flea will only end up in its denotation if the two events happen to involve the same flea. This fact is important because of the distinction between lexical and phrasal distributivity. If all verb phrases were cumulative, then under the present assumptions there would be no way to explain why 
nonatomic distributivity is not readily available at the verb phrase level, as discussed in Section 3.

I have assumed above that the type of verbs and their projections is $\langle v, t\rangle$ and that they denote predicates of events. I have argued elsewhere to the contrary that the type of verbs and verbal projections should be taken to be $\langle v t, t\rangle$ if we want to account for the interaction of verbs with quantification and other scope-taking phenomena (Champollion 2011a, 2015c). Here I stick with the more standard $\langle v, t\rangle$ assumption, in part in order to make sure the system remains compatible with the majority of existing theories and in part because the lower type is sufficient for present purposes. The relation between Champollion 2015C and the present proposal is explored in more detail in Schwarzschild 2014 and Champollion 2014. I will assume here that event predicates can combine with other event predicates by a generalized form of intersection, similarly to the predicate modification rule in Heim \& Kratzer 1998 and to the event identification rule introduced by Kratzer 1996. The idea that verbs and their arguments are combined by intersection is also argued for in Carlson 1984 and is elevated to a general principle, conjunctivism, in Pietroski 2004, 2006.

Section 2 has discussed the distinction between lexical and phrasal distributivity. As we have seen there, lexical distributivity is a property that a given verb may or may not have with respect to one of its thematic positions. I will represent lexical distributivity using meaning postulates, which put restrictions on admissible models (Hoeksema 1983). Such postulates can be used to state that whenever an (agent-)distributive predicate applies to (an event whose agent is) a plurality of individuals, then it also applies to (events whose agents are) all the individuals in the plurality. For example, the verb see is lexically distributive on (at least) its agent and theme positions, since it follows both from John and Mary saw Bill and from John saw Bill and Mary that John saw Bill. The verb lift is not distributive on its agent position, since from John and Mary lifted box $b$ it does not follow that John lifted box $b$. The verb kill is distributive on its theme but not on its agent (Lasersohn 1988, Landman 1996). This is illustrated in the following scenario (Champollion 2010b, to appear). The two outlaws Bonnie and Clyde were killed by a posse of six police officers, which included Sheriff Jordan. Given this background knowledge, (41a) entails (41b) but does not entail (41c), because Sheriff Jordan's actions might not have been sufficient by themselves to kill anyone. 
(41) a. The six police officers killed the two outlaws.

b. $\Rightarrow$ Bonnie was killed.

c. $\nRightarrow$ Sheriff Jordan killed someone.

I will adopt meaning postulates of the following form to capture the kinds of entailments that verbs license when they are distributive on one or more of their argument positions:

(42) Meaning postulate: see is distributive on its theme position $\forall e{ }^{*} \operatorname{see}(e) \rightarrow e \in{ }^{*} \lambda e^{\prime}\left({ }^{*} \operatorname{see}\left(e^{\prime}\right) \wedge \operatorname{Atom}\left(\right.\right.$ theme $\left.\left.\left(e^{\prime}\right)\right)\right)$

(43) Meaning postulate: see is distributive on its agent position $\forall e .{ }^{*} \operatorname{see}(e) \rightarrow e \in{ }^{*} \lambda e^{\prime}\left({ }^{*} \operatorname{see}\left(e^{\prime}\right) \wedge \operatorname{Atom}\left(\operatorname{agent}\left(e^{\prime}\right)\right)\right)$

The meaning postulate in (42) can be read as follows. Whenever there is a seeing event $e$, it consists of one or more seeing events $e^{\prime}$ whose themes are atoms. For example, if $e$ is an event in which John and Bill were seen, then that event consists of (in this case at least two) seeing events whose themes are atoms. From this and from the assumption that John and Bill are mereological atoms, one can conclude that John was seen and that Bill was seen. We can capture the difference between the agent and theme role of kill by adopting a meaning postulate analogous to (42) only for the theme position of that verb. In effect, (42) states that a sum of individuals can be seen only when each of them is seen. Likewise, (43) states that a sum of individuals can see something only when each of them sees something.

Algebraic semantics allows us to make distinctions between the meaning of a word and what we know about the events it describes. A meaning postulate like (42) is not strictly speaking part of the meaning of the word see, but rather it can be seen as a restriction on admissible models which captures something about "the way reality seems to be organized" (Hoeksema 1983). Accordingly, I do not take (42) and (43) to be part of the lexical entry for see. That lexical entry is shown in (44), which is assumed to be closed under sum in accordance with (36).

(44) Lexical entry for see

$\llbracket$ see $\rrbracket=\lambda e{ }^{*} \operatorname{see}(e)$

(The meaning of "see" is the property that holds of any sum of one or more seeing events.) 
Meaning postulates like (42) and (43) have the consequence that the denotation of see always has a certain higher-order property, which I have discussed elsewhere under the name stratified reference (Champollion 2010b, 2015b). I come back to stratified reference at the end of this section. The division of labor between lexical entries like (44) and higher-order properties like the ones encoded in (42) and (43) is a hallmark of algebraic semantics.

We are now ready to reformulate the $\mathrm{D}$ operator. The main idea is that this operator shifts any predicate (typically a verb phrase) into a predicate that satisfies a condition that is analogous to the one captured in the meaning postulates in (42) and (43).

I propose to redefine the operator as follows:

(45) Definition: Event-based D operator

$$
\llbracket \mathrm{D}_{\theta} \rrbracket \stackrel{\text { def }}{=} \lambda V \lambda e\left[e \in{ }^{*} \lambda e^{\prime}\left(V\left(e^{\prime}\right) \wedge \operatorname{Atom}\left(\theta\left(e^{\prime}\right)\right)\right)\right]
$$

This operator applies to an event predicate $V$, such as a verb phrase. It returns another event predicate, one which holds of any event $e$ as long as it consists of one or more events that are in $V$ and which are each mapped by the function $\theta$ to an atom. I assume that $\theta$ is a free variable that is resolved to a thematic role - formally, a function that maps events to their agents, themes, and so on. As previously mentioned, I adopt thematic uniqueness, and I model thematic roles as partial functions. This means that they can be treated as being the same kinds of things as functions that map events to their spatial and temporal locations. This will be useful once we extend the D operator to nonatomic domains like time.

The examples in (46) and (47) illustrate how the D operator in (45) works. Sentence (46) gives a baseline, a scopeless reading that does not use the D operator. Sentence (47) shows the D operator in action to model a distributive reading.

(46) The boys saw a monkey.

$\exists e\left[* \operatorname{agent}(e)=\bigoplus\right.$ boy $\left.\wedge{ }^{*} \operatorname{see}(e) \wedge \operatorname{monkey}(\operatorname{theme}(e))\right]$

(There is a potentially plural seeing event whose agents sum up to the boys, and whose theme is one monkey. That is, only one monkey is seen.)

(47) The boys [ $\mathrm{D}_{\text {agent }}[$ saw a monkey]].

$\exists e[*$ agent $(e)=\oplus$ boy $\wedge$

$\left.e \in{ }^{*} \lambda e^{\prime}\left({ }^{*} \operatorname{see}\left(e^{\prime}\right) \wedge \operatorname{monkey}\left(\operatorname{theme}\left(e^{\prime}\right)\right) \wedge \operatorname{Atom}\left(\operatorname{agent}\left(e^{\prime}\right)\right)\right)\right]$

(There is an event whose agents sum up to the boys, and this event 
consists of seeing events for each of which the agent is an atom and the theme is a monkey.)

The star operator * $\lambda e^{\prime}$ is introduced through the D operator and takes scope over the predicate monkey introduced by the theme. The representation (47) does not state explicitly that each boy sees a monkey, so it might not be clear that it is an adequate way to capture what the sentence means. This is where the background assumptions introduced above come into play. The representation (47) explicitly states that the monkey-themed events $e^{\prime}$ have atoms as agents. The fact that these atoms are boys is entailed by the background assumption that the entities in the denotation of singular count nouns are atoms, together with the background assumption that thematic roles are cumulative, as discussed above.

Because the D operator in (45) carries an index, we can capture through a simple change in coindexation the kinds of configurations that have otherwise been taken to require movement or type shifting. For example, the reading of (3ob) - repeated as (48) - in which each of the two girls gets a pumpkin pie from John can be straightforwardly accounted for.

(48) John [ $D_{\text {goal }}$ [gave a pumpkin pie]] to two girls. $=(30 b)$

(49) $\llbracket$ give a pumpkin pie $\rrbracket=\lambda e\left[{ }^{*} \operatorname{give}(e) \wedge \operatorname{pumpkin}-\operatorname{pie}(\right.$ theme $\left.(e))\right]$

(50) \to two girls $\rrbracket=\lambda e[\operatorname{two}-\operatorname{girls}(* \operatorname{goal}(e))]$

(51) $\llbracket \mathrm{D}_{\text {goal }} \rrbracket=\lambda V \lambda e\left[e \in{ }^{*} \lambda e^{\prime}\left(V\left(e^{\prime}\right) \wedge \operatorname{Atom}\left(\operatorname{goal}\left(e^{\prime}\right)\right)\right)\right]$

(52) $\llbracket D_{\text {goal }}$ give a pumpkin pie $\rrbracket=(51)((49))$ $=\lambda e[$ $\left.e \in{ }^{*} \lambda e^{\prime}\left({ }^{*} \operatorname{give}\left(e^{\prime}\right) \wedge \operatorname{pumpkin}-\operatorname{pie}\left(\operatorname{theme}\left(e^{\prime}\right)\right) \wedge \operatorname{Atom}\left(\operatorname{goal}\left(e^{\prime}\right)\right)\right)\right]$

(53) $\llbracket\left[D_{\text {goal }}\right.$ give a pumpkin pie $]$ to two girls $\rrbracket=(50) \cap(52)$ $=\lambda e[$ two-girls $(* \operatorname{goal}(e)) \wedge$ $\left.e \in{ }^{*} \lambda e^{\prime}\left({ }^{*} \operatorname{give}\left(e^{\prime}\right) \wedge \operatorname{pumpkin}-\operatorname{pie}\left(\operatorname{theme}\left(e^{\prime}\right)\right) \wedge \operatorname{Atom}\left(\operatorname{goal}\left(e^{\prime}\right)\right)\right)\right]$

(54) $\llbracket(48) \rrbracket=\exists e[\operatorname{agent}(e)=\operatorname{john} \wedge \operatorname{two}-\operatorname{girls}(* \operatorname{goal}(e)) \wedge$ $\left.e \in{ }^{*} \lambda e^{\prime}\left({ }^{*} \operatorname{give}\left(e^{\prime}\right) \wedge \operatorname{pumpkin}-\operatorname{pie}\left(\operatorname{theme}\left(e^{\prime}\right)\right) \wedge \operatorname{Atom}\left(\operatorname{goal}\left(e^{\prime}\right)\right)\right)\right]$ (There is an event whose agent is John, whose goal is two girls, and which consists of parts each of which has an atomic goal and a pumpkin pie as its theme.)

Turning now to the event-based reformulation of Schwarzschild's Part operator, this one can be seen as a generalization of Link's D operator. Instead 
of specifying the granularity parameter to be atomic, we leave it free. Accordingly, we obtain the reformulation by replacing Atom in (45) with a free variable $C$, which I will assume is anaphoric on an antecedent that can be provided by the context. This minimal change reflects the close connection between D and Part.

(55) Definition: Event-based Part operator

$$
\llbracket \operatorname{Part}_{\theta, \mathrm{C}} \rrbracket \stackrel{\text { def }}{=} \lambda V \lambda e\left[e \in{ }^{*} \lambda e^{\prime}\left(V\left(e^{\prime}\right) \wedge C\left(\theta\left(e^{\prime}\right)\right)\right)\right]
$$

What this says is that Part takes an event predicate $V$ and returns a predicate that holds of any event $e$ which can be divided into events that are in $V$ and whose $\theta$ s satisfy the contextually salient predicate $C$. Whenever $\theta$ is a sum homomorphism, this will entail that the $\theta$ s of these events sum up to the $\theta$ of $e$.

Definition (55) entails that $C$ is a set whose sum is $\theta(e)$. In this way, the notion of cover emerges naturally and does not need to be separately defined. This may be seen as a conceptual advantage over Schwarzschild 1996.

The example in (56) shows how my reformulation of Schwarzschild's Part operator works. The example is repeated from the shoe sentence (3). I assume for concreteness that the shoes play the theme role in this sentence. I assume that $C$ is resolved here to a contextual predicate that I call pair and that applies to a sum of two shoes just in case they are one of the pairs of shoes on display.

(56) The shoes [Part theme,pair [cost fifty dollars]].

$\exists e .{ }^{*}$ theme $(e)=\bigoplus$ shoe $\wedge$ Part theme,pair $(\llbracket$ cost fifty dollars $\rrbracket)(e)$

$\Leftrightarrow \exists e .{ }^{*}$ theme $(e)=\bigoplus$ shoe $\wedge$

$$
e \in{ }^{*} \lambda e^{\prime}\left[e^{\prime} \in \llbracket \text { cost fifty dollars } \rrbracket \wedge \operatorname{pair}\left(\operatorname{theme}\left(e^{\prime}\right)\right)\right]
$$

(There is a plural event whose themes sum up to the shoes and which consists of costing-fifty-dollars events with pairs as themes.)

The event-based reformulation of the D and Part operators allows us to think of distributivity as a parametrized operator. The D operator only has one parameter, $\theta$, which specifies the thematic role over which it distributes. The Part operator has an additional granularity parameter, $C$, which corresponds to Schwarzschild's cover variable and which specifies the size of the things over which it distributes. These two parameters are at the core of strata theory, as discussed in Section 1 and in Champollion 2010b. The dimension parameter of strata theory corresponds to the $\theta$ parameter on 
our operators, and it indicates the domain that contains the entities over which the operator distributes. The granularity parameter of strata theory corresponds to the $C$ parameter of the Part operator, and it indicates the size of the entities over which the operator distributes. I assume that the setting "granularity=atom" blocks the setting "dimension=time" because time is continuous and noncount - either there are no atoms to distribute over, or they are not accessible to natural language semantics (von Stechow 2009). In Champollion 2016, I rely on this interaction in order to explain certain typological facts involving distance-distributive items.

The two operators D and Part may be seen as special cases of the general scheme of stratified reference (Champollion 2010b, 2017). There are two related definitions of stratified reference, a "restricted" and a "universal" one. Both of them apply to a property $P$ and are parametrized for dimension $d$ and granularity $g$. The restricted definition is furthermore relativized to a specific entity or event, similarly to the D and Part operators:

(57) Definition: Stratified reference

Let $d$ (a dimension) be any function from entities of type $\alpha$ to entities of type $\beta$, and let $g$ (a granularity level) be any predicate of entities of type $\beta$. Let $P$ range over predicates of type $\langle\alpha, t\rangle$ where $\alpha$ is either $e$ or $v$, and let $x$ range over entities of type $\alpha$. Then:

$\mathrm{SR}_{d, g} \stackrel{\text { def }}{=} \lambda P \lambda x\left[x \in{ }^{*} \lambda y[P(y) \wedge g(d(y))]\right]$

$(P$ stratifies $x$ along dimension $d$ with granularity $g$ if and only if $x$ consists of one or more parts in $P$ that are each mapped by $d$ to something in $g$.)

From this definition, we obtain the $\mathrm{D}_{\theta}$ operator in (45) by setting $\alpha$ to $v, \beta$ to $e, d$ to $\theta$, and $g$ to Atom, and by coindexing the operator with $\theta$. We obtain the Part ${ }_{\theta, C}$ operator in (55) with the same settings, except that $g$ is set to $C$.

By quantifying over all values of $x$, we obtain the universal version of stratified reference (see Champollion 2015a: 235):

Definition: Universal stratified reference

$\mathrm{SR}_{d, g} \stackrel{\text { def }}{=} \lambda P \forall x\left[P(x) \rightarrow \mathrm{SR}_{d, g}(P)(x)\right]$

$(P$ has universal stratified reference with dimension $d$ and granularity $g$ if and only if $P$ stratifies everything in $P$.)

Stratified reference is based on the idea that events can be thought of as regions in a high-dimensional space where each dimension represents one 
of the possible thematic roles of the event. When a predicate $P$ stratifies an event $e$ along a dimension $d$ with granularity $g$, we can imagine that $e$ can be sliced along direction $d$ into layers with thickness $g$ such that each layer is in $P$. Strata theory uses this concept to connect the present theory with counterparts in aspect and measurement (Champollion 2010b, 2015b). In its original formulation, strata theory was formalized in terms of the universal version of stratified reference in (58). The restricted version is advocated in Schwarzschild 2015 for reasons unrelated to the D and Part operators. I have subsequently adopted it in Champollion 2015a, 2017.

This similarity to restricted stratified reference is not the only reason why I adopt the definitions in (45) and (55) over alternative formulations. Another reason is that these definitions provide access to the sum of the events over which the relevant predicate is distributed. This sum event will be of central importance throughout the rest of this paper and Champollion 2016. It is absent not only from traditional definitions of these operators (because they do not invoke events), but also from previous proposals on how to reformulate distributivity operators in event semantics. The next section reviews one of these proposals.

\section{Previous work on event-based distributivity operators}

Reformulating distributivity operators in event semantics is one of the topics of Lasersohn 1998. That paper shows a way of generalizing Link's and other distributivity operators so that they apply to other positions than the subject position both in eventless and in event-based frameworks. The entry in (59) is a special case among these different combinations, namely the VP-level variant of an event-based version of Link's D operator.

(59) Distributivity operator over events (Lasersohn)

$$
\llbracket \mathrm{D} \rrbracket=\lambda P_{\langle e, v t\rangle} \lambda x \lambda e \forall y\left[y \leq_{A t o m} x \rightarrow \exists e^{\prime}\left[e^{\prime} \leq e \wedge P(y)\left(e^{\prime}\right)\right]\right]
$$

Lasersohn's operator applies to a predicate of type $\langle e, v t\rangle$. It is based on the assumption that a verb phrase like smile that is about to combine with it is represented as something like $\lambda x \lambda e[\operatorname{smile}(e) \wedge \operatorname{agent}(e)=x]$. The entry in (59) does not represent Lasersohn's entire proposal, but it is the part that is most closely related to mine. A very similar operator is proposed in LaTerza 2014. Both authors credit the basic idea behind their event-based operators to Schein 1993. In the following, for concreteness I only talk about Lasersohn's proposal, but my observations apply equally to LaTerza's operator. 
One difference between Lasersohn's proposal in (59) and my proposal in (45) consists in the way the operators access the plural entity over which they distribute. The D operator in (59) accesses that plural entity by combining with a predicate of type $\langle e, v t\rangle$. In contrast to Lasersohn, I do not rely on the implicit assumption that the $\mathrm{D}$ operator is adjacent to a constituent denoting that entity. My operator in (45) is parametrized for the relevant thematic role. This thematic role can be supplied by coindexation with an appropriate $\theta$ role head (Champollion 2016). Maintaining the adjacency assumption would make it harder to build on the D operators to account for the phenomenon of distance distributivity, as I do in Champollion 2016.

Another, more substantial difference consists in the way in which the operators access the events over which they distribute. My operator in (45) uses algebraic closure over events with atomic agents, while Lasersohn's operator uses universal quantification over individuals. The difference between the formulations is apparent in the different representations that result from inserting a D operator into the sentence The children took a nap before existential closure applies. (The subformula $y \leq_{\text {Atom }} \oplus$ child is equivalent to $\operatorname{child}(y)$ on the assumption that children are mereological atoms.)

\section{a. Lasersohn's representation:}

$\lambda e \forall y\left[y \leq_{\text {Atom }} \oplus\right.$ child $\rightarrow$

$\left.\exists e^{\prime}\left[e^{\prime} \leq e \wedge * \operatorname{take}\left(e^{\prime}\right) \wedge \operatorname{agent}\left(e^{\prime}\right)=y \wedge \operatorname{nap}\left(\operatorname{theme}\left(e^{\prime}\right)\right)\right]\right]$

b. My representation:

$\lambda e\left[{ }^{*} \operatorname{agent}(e)=\bigoplus\right.$ child $\wedge$

$$
\left.e \in{ }^{*} \lambda e^{\prime}\left[{ }^{*} \operatorname{take}\left(e^{\prime}\right) \wedge \operatorname{Atom}\left(\operatorname{agent}\left(e^{\prime}\right)\right) \wedge \operatorname{nap}\left(\text { theme }\left(e^{\prime}\right)\right)\right]\right]
$$

Lasersohn's representation (6oa) applies to all events that contain a napping subevent (that is, a "taking" subevent whose theme is a nap) for each child, even if they also contain other subevents. My representation applies to all events that contain a napping subevent for each child and nothing else. Thus, Lasersohn's solution suffers from leakage. It does not give special status to the sum of all of the subevents over which the D operator distributes. Instead, it applies not only to that sum but also to any event that contains that sum. Through leakage, Lasersohn's operator makes any predicate it modifies persistent. That is, whenever the modified predicate applies to an event $e$, it also applies to any event of which $e$ is a part. Eckardt (1998: Chapter 4) argues convincingly that the persistency assumption is problematic in event semantics, contra Lasersohn 1992, 1998. I will spell out one facet of this problem shortly. By contrast, my representation (6ob) only applies to the 
sum itself. This is due to the way the star operator works. To expand on the geometrical example given earlier, if $x$ is a square and $P$ is the property of being a triangle, then $x$ satisfies ${ }^{*} P$ because $x$ can be divided into triangles without leaving anything out. If $x$ is a circle instead of a square, it does not satisfy ${ }^{*} P$. Even though every circle contains infinitely many triangles, the curvature of the circle makes it impossible to divide it into triangles without leaving anything out (setting aside sums of uncountably infinite triangles).

Leakage causes a problem in connection with subjects and other arguments and modifiers that take scope over the distributivity operator. This will be relevant in Section 6, where I will argue that the distributivity operator can also occur in the scope of for-adverbials. The problem can be illustrated with nondistributive adverbials such as in 30 minutes and from 2pm to $4 \mathrm{pm}$ (Eckardt 1998: Chapters 4 \& 5) or unharmoniously (Schein 1993: Chapter 1):
a. In 30 minutes, Alma put each ball into a box.
b. From $2 \mathrm{pm}$ to $4 \mathrm{pm}$, Bertha took a nap and watered the tulips.
c. Unharmoniously, every organ student sustained a note on the Wurlitzer.

The predicates in these examples hold of an event even if they do not hold of its parts. For example, (61c) is true if the ensemble event was unharmonious even if the same cannot be said of any one student's note. We can now illustrate the problem caused by leakage. Let $L$ stand for (6oa) and let $M$ stand for my event predicate (6ob). Imagine a group of children in a preschool napping from $2 \mathrm{pm}$ to $3 \mathrm{pm}$ and then playing from $3 \mathrm{pm}$ to $4 \mathrm{pm}$. For each child there is a napping event followed by a playing event. Call the sum of all the napping events $e_{\text {nap }}$. By lexical cumulativity, this sum itself counts as a napping event, and its agent is the children; hence it satisfies both Lasersohn's predicate $L$ and my predicate $M$. Call the sum of all playing events $e_{\text {play }}$, a playing event whose agent is again the children. Let $e_{\text {nap } \oplus \text { play }}$ be the sum of $e_{\text {nap }}$ and $e_{\text {play }}$. This does not satisfy $M$ because it contains extraneous material: it is not a napping event but the sum of a napping and of a playing event, and the two do not overlap. But $e_{\text {nap } \oplus \text { play }}$ satisfies $L$, because by virtue of containing $e_{\text {nap }}$, it contains a napping event for every child. By assumption, $e_{\text {nap }}$ does not take place from $2 \mathrm{pm}$ to $4 \mathrm{pm}$, but $e_{\text {nap } \oplus \text { play }}$ does. Sentence (62) is false in this scenario. If the D operator is applied to nap, then on Lasersohn's account, this sentence is represented as (62a), while on my account it is represented as (62b). 
Lucas Champollion

(62) From $2 \mathrm{pm}$ to $4 \mathrm{pm}$, the children took a nap.

a. $\exists e[e \in \llbracket$ from $2 \mathrm{pm}$ to $4 \mathrm{pm} \rrbracket \wedge L(e)]$

b. $\exists e[e \in \llbracket$ from $2 \mathrm{pm}$ to $4 \mathrm{pm} \rrbracket \wedge M(e)]$

Now $e_{n a p \oplus \text { play }}$ satisfies both $L$ (by leakage) and the predicate from $2 p m$ to $4 \mathrm{pm}$ (by assumption). Therefore, Lasersohn's D operator wrongly predicts that (62) is judged true, namely in virtue of $e_{\text {nap } \oplus \text { play. }}$

A reviewer wonders whether the leakage problem could be avoided by combining Lasersohn's operator with minimization or some related operation. This will not work, because events are wholly but not necessarily minimally relevant to the truth of the propositions they verify (see Fine 2012). Let $\min (V)$ denote the set of all entities $e$ such that $V$ applies to $e$ but not to any of the proper parts of $e$, and consider the following amendment to Lasersohn's operator (59):

$$
\lambda P_{\langle e, v t\rangle} \lambda x \lambda e . e \in \min \left(\lambda e^{\prime} \forall y\left[y \leq_{\text {Atom }} x \rightarrow \exists e^{\prime \prime}\left[e^{\prime \prime} \leq e^{\prime} \wedge P(y)\left(e^{\prime \prime}\right)\right]\right]\right)
$$

When this version is inserted into The children took a nap, the resulting representation before existential closure applies to all events that are minimal with respect to the property of containing a napping subevent for each child. In the example above, $e_{n a p \oplus p l a y}$ will not be such an event, because it is not minimal with respect to that property. This is as desired.

But in the context of event semantics, the minimality operation has unintended consequences. For one thing, there may not always be any minimal events. Take a predicate with the subinterval property, such as sit. If we assume that sit is distributive on its agent position and that time is nonatomic, applying (63) to it returns the empty set because there are no minimal sitting events. A possible reaction is to replace the minimality condition in (63) by an exemplification condition (Kratzer 2016). An entity e exemplifies a predicate $V$ just in case $V$ holds of $e$ and either of none of the proper parts of $e$ (as in the case of minimality) or of all of them. This avoids the problem just mentioned. However, both minimality and exemplification fail to give us access to events of the required length. Even if minimal napping events exist, their runtime will certainly be shorter than one hour. This means that in the scenario above where each child takes a nap from $2 \mathrm{pm}$ to $3 \mathrm{pm}$, The children took a nap from $2 \mathrm{pm}$ to $3 \mathrm{pm}$ is predicted false, contrary to fact. Even more sophisticated notions of minimality have also turned out to be problematic (Eckardt 1998: Chapter 4). Rather than pursuing this route further, I will adopt the operator in (45). This operator not only avoids the problems just 
mentioned. It is also more simple and concise than (63) plus exemplification, and as we have seen, it makes the parallel with strata theory clear.

As this section has shown, to avoid leakage we need to reformulate the distributivity operator in a way that makes sure that no extraneous material can find its way into the sum event. This ensures that the output of the operator is the right kind of predicate to be passed on to the next argument or adjunct of the verb. In the previous examples, this was the event modifier from $2 \mathrm{pm}$ to $4 \mathrm{pm}$. In the next section, I will exploit this property of the distributivity operator in another way: it will apply to a verb phrase as before, but its output will serve as the input to a for-adverbial, which in turn will pass it on to the subject of the sentence after making sure that the output of the distributivity operator is atelic.

\section{The scopal behavior of for-adverbials}

We have seen in Sections 2 and 3 that covarying interpretations of indefinites and numerals are the signature property of phrasal distributivity. In this respect, covert phrasal distributivity is of course similar to overt universal quantification:

(64) a. The girls are wearing a black dress. $=(2)$

b. Every girl is wearing a black dress.

c. Every day, Mary wore a black dress.

As we will see in this section, for-adverbials are often analyzed as involving universal quantification over temporal intervals. From this point of view, one would expect them to act similarly to overt universal quantifiers like every girl or every day. Yet it has often been observed that they do not behave the same way as overt universal quantifiers do (e.g., Carlson 1977, Zucchi \& White 2001, van Geenhoven 2004, Kratzer 2007). I will argue that phrasal distributivity is not triggered by for-adverbials, but by intervening modifiers like every day and by distributivity operators that arise in contexts where a temporal partition is salient.

Normally, for-adverbials cannot give rise to covariation in singular indefinites. The sentences in (65), adapted from Kratzer 2007, are supposed to be understood as uttered out of the blue, without any special context. I write $\exists>\forall$ for an interpretation in which the indefinite involves reference to a single entity and $\forall>\exists$ for an interpretation in which it involves reference to multiple entities. 
(65) a. I dialed a wrong phone number for five minutes. $\exists>\forall ; * \forall>\exists$

b. John pushed a cart for an hour. $\quad \exists>\forall ; * \forall>\exists$

c. She bounced a ball for 20 minutes. $\quad \exists>\forall ; * \forall>\exists$

d. He kicked a wall for a couple of hours. $\quad \exists>\forall ; * \forall>\exists$

e. She opened and closed a drawer for half an hour. $\exists>\forall ; * \forall>\exists$

f. I petted a rabbit for two hours. $\quad \exists>\forall ; * \forall>\exists$

It would be plausible for (65a) to have an interpretation like Over and over again over the course of five minutes I dialed a different wrong phone number, and similarly for the other examples. But this kind of interpretation is systematically absent from such examples when they are uttered out of the blue. Even in cases where the wide-scope interpretation of the indefinite is pragmatically odd, it is still the only one available. Example (66a) is repeated from (5a); (66b) and (66c) are from Deo \& Piñango 2011.
a. ??John found a flea for a month.
$? ? \exists>\forall ; * \forall>\exists$
b. ??John noticed a discrepancy for a week.
$? ? \exists>\forall ; * \forall>\exists$
c. ??John discovered a new proof for a week.
$? ? \exists>\forall ; * \forall>\exists$

The same behavior can be observed if we replace the singular indefinite with certain other types of quantifiers, such as plural indefinites. For example, the only available interpretation of (67) is the one in which the plural indefinite thirty zebras involves reference to a single set of thirty zebras.

(67) John saw thirty zebras for three hours.

Even in German, a language in which inverse scope is normally not available, indefinites in the scope of for-adverbials cannot covary. Each of the following two sentences is a possible translation of (65a) and must involve reference to a single phone number (Kratzer 2007).

a. Ich hab' fünf Minuten lang eine falsche Telefonnummer I have five minutes long a wrong telephone number gewählt.

dialed

b. Ich hab' eine falsche Telefonnummer fünf Minuten lang I have a wrong telephone number five minutes long gewählt.

dialed 
The behavior just described does not hold across the board for all types of noun phrases. Bare plurals and mass nouns do not have to take distributive wide scope over for-adverbials (Carlson 1977, Verkuyl 1972, Dowty 1979). This can be seen in the sentences in (69) and (70), taken from Dowty 1979:

(69) a. John found fleas on his dog for a month.

b. John discovered crabgrass in his yard for six weeks.

(70) a. Tourists discovered that quaint little village for years.

b. Water leaked through John's ceiling for six months.

VP-level and sentential predicates with bare noun phrases are generally compatible with for-adverbials and do not give rise to the phenomena described above. For example, (69a) is compatible with the plausible interpretation in which John finds different fleas on his dog over the course of a month and finds each of them only once.

Even singular indefinites in the scope of for-adverbials can involve reference to multiple individuals when a temporal universal quantifier intervenes, as in examples (6) and (7b), repeated here as (71a) and (71b).

(71) a. John found a flea on his dog every day for a month.

b. Jim hit a golf ball into the lake every five minutes for an hour.

In these examples, the indefinite can covary with the universal quantifier. As we have seen, (71a) is true in a situation where John found a different flea on his dog every day, and (71b) is compatible with Jim hitting a different golf ball into the lake every five minutes. Other interveners allow indefinites under for-adverbials to involve reference to multiple entities. These include pluractional adverbials like day after day (see Beck \& von Stechow 2007) and context-dependent temporal definites such as at breakfast (Deo \& Piñango 2011):

(72) a. John found a flea on his dog day after day for a month.

b. Jane ate an egg at breakfast for a month.

Covariation is also possible when a salient level of granularity can be inferred from context (see Ferreira 2005: 130). To repeat the example from Section 1, in a context where the daily pill intake of patients is salient, such as a hospital, sentence (73) is licit despite the fact that it does not require any pill to be taken more than once. 
Lucas Champollion

(73) Context: discussing daily pill intake

The patient took two pills for a month and then went back to one pill.

Example (74), from Deo \& Piñango 2011, shows the same point. It is understood as involving reference to several snowmen.

(74) We built a huge snowman in our front yard for several years.

This is presumably because world knowledge makes the cycle of seasons salient here, suggesting that they built a different snowman every winter.

Finally, example (75) is adapted from Landman \& Rothstein 2010 and is to be understood in a context where the bicycle is designed to carry around three children at a time, and was used over a period of twenty years to carry different sets of three children around.

(75) This bicycle carried three children around Amsterdam for twenty years.

In the following, $\tau$ stands for the runtime function that maps each event to the location in time at which it occurs. I assume that $\tau$ has the properties ascribed to it in Krifka 1998. Specifically, I assume that $\tau$ is a sum homomorphism. This means that runtimes can be discontinuous. Take for example an event $e_{1}$ whose runtime is the interval from 12:30pm to $1 \mathrm{pm}$, and an event $e_{2}$ whose runtime is the interval from $5 \mathrm{pm}$ to $6: 15 \mathrm{pm}$. The sum of these two events, $e_{1} \oplus e_{2}$, will have a discontinuous runtime, namely the sum of the interval from 12:30pm to $1 \mathrm{pm}$ and the interval from $5 \mathrm{pm}$ to $6: 15 \mathrm{pm}$. Lexical cumulativity causes most verbs to involve reference to many discontinuous events; for example, find applies to sums of finding events that may have arbitrarily long gaps between them.

Theories of for-adverbials can be classified into two groups, which I will review here schematically as Theory A and Theory B. Theory A predicts that all indefinites in the scope of for-adverbials should covary, while Theory B predicts that none of them should. Neither of these theories turns out to account for the facts by itself. I will propose to account for the limited covariation by adding a distributivity operator to Theory B. Roughly these two kinds of theories (but without the distributivity operator) are also discussed by Zucchi \& White (2001). In my discussion of the two classes of theories I will use two shorthands, regular and atelic, to hide some complexities that do not affect the main point of comparison. I will explain these shorthands below. 
Covert distributivity in algebraic event semantics

On Theory A, the meaning of a for-adverbial can be represented as something like (76):

(76) «for an hour $\rrbracket($ Theory A)

$$
\begin{aligned}
& =\lambda V \exists t[\operatorname{hours}(t)=1 \wedge \operatorname{regular}(t) \wedge \\
& \left.\forall t^{\prime}\left[t^{\prime} \text { is a very short part of } t \rightarrow \exists e\left[V(e) \wedge \tau(e)=t^{\prime}\right]\right]\right]
\end{aligned}
$$

Theory A says that a for-adverbial is represented as a universal quantifier over very short subintervals of a regular interval, a bit as if it was the temporal counterpart of every. By contrast, Theory B says that a for-adverbial is represented in a way that passes the denotation of the verb phrase up unchanged as long as it is both regular and atelic. On Theory $\mathrm{B}$, the meaning of a for-adverbial can be represented as in (77) (I write $\lambda e: \phi . \psi$ for the partial function that is defined whenever $\phi$ holds, and that maps $e$ to $\psi$ whenever it is defined):

(77) «for an hour $\rrbracket($ Theory B)

$$
=\lambda V \lambda e: \operatorname{regular}(\tau(e)) \wedge \operatorname{atelic}_{e}(V) . V(e) \wedge \operatorname{hours}(\tau(e))=1
$$

Theory A is somewhat similar to the influential theory of for-adverbials in Dowty 1979. However, there is an important difference because Dowty analyzes for-adverbials as universal quantifiers over subintervals rather than over instants. These do not have to be proper subintervals, so the predicate is required to hold at the entire interval described by the for-adverbial, in addition to all of its subintervals. A similar theory, in which for-adverbials quantify over "relevant" subintervals (whatever that may mean), is found in Moltmann 1991. Theory B is found in various forms in Krifka 1989a,b, 1998. It is explicitly defended against Theory A in Kratzer 2007.

Let me now explain what I mean by the shorthands regular and atelic. The first shorthand, regular, stands for a theory that regulates the amount of discontinuity that for-adverbials can tolerate (Vlach 1993). Even when we keep the verb and adverbial constant, this amount can vary considerably from one case to another, subject to pragmatic constraints. This is illustrated in the following pair of examples (Barbara Partee p.c. in Vlach 1993). Sentence (78a) requires Mary to sleep almost continuously; sentence $(78 \mathrm{~b})$ is compatible with an ordinary sleeping pattern of about eight hours a day.

(78) a. Mary slept for a week.

b. Mary slept in the attic for a week. 
These constraints ultimately need to be addressed by any theory of foradverbials, and there are a few that do so (Piñón 1999, Landman \& Rothstein 2012a,b). I will not discuss these theories here because this issue is not central to the following discussion. Still, I will carry the shorthand regular along as a reminder that this part will need to be filled in.

The shorthand atelic encodes the principal requirement of for-adverbials. I argue in Champollion 2017: Chapters $5 \& 6$, that it can be formulated in terms of stratified reference as in (57), with a dimension and a granularity parameter, just like the theory of distributivity presented here. The requirement can be formulated in a way that is similar to the meaning postulate in (42), except that the dimension and granularity parameters involved are set to $\tau$ and to the set of proper parts of the temporal trace of the event in question. When this is spelled out, it amounts to the following (Champollion 2015a):

(79) Atelicity requirement on $\boldsymbol{V}$

$\operatorname{atelic}_{e}(V) \stackrel{\text { def }}{=} e \in{ }^{*} \lambda e^{\prime}\left[V\left(e^{\prime}\right) \wedge \tau\left(e^{\prime}\right)<\tau(e)\right]$

(The $V$-ing event $e$ consists of $V$-ing parts whose runtimes are shorter than its own.)

The behavior of indefinites in examples like (65) and (66), some of which are repeated in (80), is surprising on Theory A, where a for-adverbial for an hour is interpreted as at each very short part of the relevant interval:

a. I dialed a wrong phone number for five minutes.

$=(65 \mathrm{a})$

b. ??John found a flea for a month.

$=(66 \mathrm{a})$

On Theory A, in order to account for this behavior the indefinite would have to be interpreted with wide scope over the for-adverbial. In (8ob), the resulting interpretation is pragmatically odd because it is unusual to find the same flea repeatedly. The narrow-scope interpretation would be much more plausible, but it is not available out of the blue. One might try to account for these facts by stipulating obligatory quantifier raising of the indefinite above the for-adverbial, as suggested by Krifka (1998). But this will not work in German, a surface-scope language whose for-adverbials behave as in English, as we have seen in (68) (Kratzer 2007). Moreover, if for-adverbials forced all indefinites in their syntactic scope to move and take semantic scope above them, then every day should not be able to prevent this from happening in this case, contrary to what we have seen in (71a) (Zucchi \& White 2001). Thus, obligatory quantifier raising is not an option. 
Neither Theory A nor Theory B is able to account for the limited ability of indefinites to covary in the scope of for-adverbials, at least not without further modifications. In a nutshell, Theory A predicts that they should always covary and Theory B predicts that they should never covary. On Theory A, the scopal behavior of for-adverbials is surprising when compared with the familiar scopal behavior of the universal quantifier every. In contrast to every, which can take scope anywhere in its clause, for-adverbials always seem to take narrow semantic scope with respect to singular indefinites in their syntactic scope, except in cases like (71a) through (75). Thus the ability of for-adverbials to give rise to quantifier scope ambiguities is much more limited than we would expect. Theory B, on the other hand, is not a good fit either, because by itself it predicts no scope ambiguities at all.

Clearly, neither of the two classes of theories can model the covariation of indefinites while taking the role of context into account. The first part of the paper has already introduced the tool we need to account for contextually limited covariation: a nonatomic distributivity operator. I will assume that this operator can intervene between the verb phrase and the for-adverbial in the same way as overt adverbs like every day/hour/month, and with a similar effect on the behavior of indefinites in their scope. In a nonatomic domain like time, atomic distributivity is not an option; so when the dimension parameter of the distributivity operator involved is instantiated to $\tau$ (runtime), its granularity parameter cannot be set to Atom. I assume that nonatomic levels of granularity such as day and month are only available when they are salient, just as in the case of Schwarzschild's nonatomic Part operator. On this view, then, indefinites that seem to covary with a for-adverbial actually covary with a covert Part operator.

I will now implement my proposal by extending Theory B with a temporal version of the Part operator, which is related to the notion of a contextually determined partition that originated independently in Moltmann 1991 and in Deo 2009. These accounts place the anaphoricity on context into the foradverbial itself. This approach is also advocated in Deo \& Piñango 2011. I have argued elsewhere that it is the distributivity operator and not the foradverbial that is anaphoric on context (Champollion 2013). As we have seen, the Part operator introduces a contextual variable that is resolved to a cover. I will identify this cover with the granularity parameter day/hour/month.

Let us first consider cases where Theory B works without modifications, namely those in which the indefinite does not covary. Given our background 
assumptions, Theory B immediately predicts that the indefinite in (65b), repeated here as (81), must involve reference to a single cart.

$$
\text { John pushed a cart for an hour. }
$$$$
=(65 \mathrm{~b})
$$

This prediction is obtained based on the representation in (82) of the denotation of the verb phrase push a cart, which assumes lexical cumulativity as in (36):

$\llbracket$ push a cart $\rrbracket=\lambda e\left[{ }^{*} \operatorname{push}(e) \wedge \operatorname{cart}(\operatorname{theme}(e))\right]$

(True of any pushing event or sum of pushing events whose theme is one and the same cart.)

Even though the verbal denotation push is pluralized here, the predicate cart is not pluralized. That is, the verb phrase only applies to events whose theme is exactly one cart, even if these events may be sums of other events. In connection with the entry (77), it predicts that the entire event over which sentence (81) existentially quantifies must have a single cart as its theme:

$$
\begin{aligned}
& \llbracket \text { John pushed a cart for an hour } \rrbracket \\
& =\exists e: \operatorname{regular}(\tau(e)) \wedge \operatorname{atelic} e\left(\lambda e^{\prime}\left[{ }^{*} \operatorname{push}\left(e^{\prime}\right) \wedge \operatorname{cart}\left(\operatorname{theme}\left(e^{\prime}\right)\right)\right]\right) \text {. } \\
& {\left[* \operatorname{agent}(e)=j \wedge{ }^{*} \operatorname{push}(e) \wedge \operatorname{cart}(\operatorname{theme}(e)) \wedge \operatorname{hours}(\tau(e))=1\right]} \\
& \text { (Defined if and only if push a cart is atelic. If defined, true if and only } \\
& \text { if there is a regular pushing event whose theme is one cart, whose } \\
& \text { agent is John, and whose runtime measures one hour.) }
\end{aligned}
$$

Lexical cumulativity accounts for the behavior of achievement verbs like find even though these verbs are normally understood to have very short runtimes (Kratzer 2007). For example, a sentence like (84) (repeated from (66a)) is now predicted to entail that there was a finding event $e$ which lasted a month and whose theme is a flea.

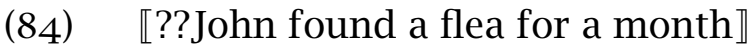

$=\exists e: \operatorname{regular}(\tau(e)) \wedge \operatorname{atelic}_{e}\left(\lambda e^{\prime}\left[* \operatorname{find}\left(e^{\prime}\right) \wedge\right.\right.$ flea $\left(\right.$ theme $\left.\left.\left.\left(e^{\prime}\right)\right)\right]\right)$.

$\left[* \operatorname{agent}(e)=j \wedge{ }^{*}\right.$ find $(e) \wedge$ flea(theme $\left.\left.(e)\right) \wedge \operatorname{months}(\tau(e))=1\right]$ (Defined if and only if find a flea is atelic. If defined, true if and only if there is a regular finding event whose theme is one flea, whose agent is John, and whose runtime measures one month.)

The lexical cumulativity assumption allows this finding event to consist of several individual findings, which may have very short runtimes. It allows 
phrasal predicates like find a flea to involve reference to plural events only to the extent that the verb predicate (find in this case) already does so. The object a flea is not affected by pluralization and continues to involve reference to a singular flea. This means that sentence (84) requires a single flea to have been found repeatedly over the course of a month.

The formula in (84) does not require John to have been searching uninterruptedly at every moment of the month, since the runtimes of events may be discontinuous. I assume that the function months maps a discontinuous interval to the same number as the smallest continuous interval that contains it.

Without further modifications, Theory B predicts that a singular indefinite in the scope of for-adverbials should always involve reference to a single entity, consistent with what we have seen in the examples in (65) but contrary to what we have seen in examples (73), (74), and (75). The only criterion that distinguishes these two groups of examples is the availability of a supporting context. We observed an analogous effect in Section 3, when we considered the following examples:

(85) a. The shoes cost fifty dollars (i.e., per pair).

b. The suitcases weigh fifty pounds.

Let me now add a distributivity operator to Theory B that is anaphoric on a contextually salient temporal cover. This will allow context to rescue examples like (73), (74), and (75), in the same way as examples like (85a) involve a distributivity operator over shoes which is anaphoric to a salient cover of the collection of shoes in question. Out of the blue, predicates like find a flea in examples like (66a) are unable to distribute over days for the same reason that also prevents predicates like weigh fifty pounds in examples like (85b) from distributing over pluralities of suitcases. Both would need a Part operator in order to distribute, but that operator is not licensed out of the blue.

The distributivity operator in Section 4 was relativized to two parameters: a thematic role, which was always set to agent or theme for the examples we considered, and a level of granularity, which was assumed to be either atomic or provided by context. I assume that the thematic role parameter can also be set to $\tau$, or runtime. Given that we take time to be a nonatomic domain, setting the thematic role parameter to $\tau$ should be incompatible with setting the granularity parameter to Atom. To put it differently, there is 
no atomic-level distributivity operator for time. Only the Part operator can distribute over time.

Let us now instantiate the Part operator in (55) with suitable dimension and granularity parameters. I will instantiate the dimension parameter as $\tau$.

\section{Definition: Event-based temporal Part operator $\llbracket \operatorname{Part}_{\tau, \mathrm{C}} \rrbracket \stackrel{\text { def }}{=} \lambda V \lambda e\left[e \in{ }^{*} \lambda e^{\prime}\left(V\left(e^{\prime}\right) \wedge C\left(\tau\left(e^{\prime}\right)\right)\right)\right]$}

(Takes an event predicate $V$ and returns a predicate that holds of any event $e$ which consists entirely of events that are in $V$ and whose runtimes satisfy the contextually salient 'cover predicate' $C$.)

The insertion of this temporal instantiation of Part can be seen as a repair strategy that shifts the meaning of a predicate in order to satisfy the atelicity presupposition of a for-adverbial. For example, take a pill by itself is punctual and telic, an achievement predicate in the terminology of Vendler 1957. Even lexical cumulativity does not change this fact, since no two such events can involve the same pill. But after the operator in (86) has been applied, the shifted predicate is now iterative. Depending on the value to which the variable $C$ of this operator is resolved, this shifted predicate can be roughly paraphrased as take a pill every day, or take a pill every hour, etc., except that such overt quantifiers lack the context-sensitivity of (55) and come with a consecutivity requirement I will discuss shortly. This kind of predicate can be empirically and formally shown to be atelic. Empirically, these predicates are atelic because they are compatible with for-adverbials, as shown by examples like (87), adapted from (71a).

(87) The patient took a pill every day for a month.

Formally, under an appropriate definition of atelicity formulated in terms of strata theory, as in (79), it can be proved that any predicate that results from the application of the Part operator is atelic (Champollion 2010b). Roughly, the proof says that when atelicity is formulated as in (79), an atelic predicate must have exactly the properties that the output of the temporal Part operator in (86) has, so long as the cover predicate is fine-grained enough.

We are now ready to explain the difference between examples (66a) and (73), repeated here:

\section{Uttered out of the blue:}

??John found a flea for a month. 
Covert distributivity in algebraic event semantics

(89) Context: discussing daily pill intake

The patient took two pills for a month and then went back to one pill.

In example (89), I assume that the verb phrase take two pills has the following denotation prior to the application of the distributivity operator:

(90) 【take two pills $\rrbracket$

$=\lambda e\left[{ }^{*} \operatorname{take}(e) \wedge{ }^{*} \operatorname{pill}\left({ }^{*} \operatorname{theme}(e)\right) \wedge\left|{ }^{*} \operatorname{theme}(e)\right|=2\right]$

This predicate applies to events in which a total of two pills are taken. It cannot combine directly with the for-adverbial because it is not atelic. The operator in (86) can be used as a repair strategy, provided that it is available. In (89), this is the case, because there is a salient level of granularity in the context and $C$ can be resolved to it. That is, (89) is uttered in a context that makes salient a set of intervals that are no longer than a day - either the set $\lambda t$.days $(t) \leq 1$ or one of its subsets. This is as opposed to (88), which is uttered in a default context that does not contain anything that $C$ can be resolved to.

This explains the contrast between (88) and (89). But how does (89) acquire its meaning? I have suggested that it involves the application of Part $_{\tau, \lambda t \text {.days }(t) \leq 1}$ to its verb phrase. The result of this operation is given in (91):

$$
\begin{aligned}
& \operatorname{Part}_{\tau, \lambda t \text {.days }(t) \leq 1}\left(\lambda e\left[{ }^{*} \operatorname{take}(e) \wedge{ }^{*} \operatorname{pill}\left({ }^{*} \text { theme }(e)\right) \wedge \mid{ }^{*} \text { theme }(e) \mid=2\right]\right) \\
& =\lambda e . e \in{ }^{*} \lambda e^{\prime}\left({ }^{*} \operatorname{take}\left(e^{\prime}\right) \wedge{ }^{*} \operatorname{pill}\left({ }^{*} \operatorname{theme}\left(e^{\prime}\right)\right) \wedge \mid{ }^{*} \text { theme }\left(e^{\prime}\right) \mid=2\right. \\
& \left.\wedge \operatorname{days}\left(\tau\left(e^{\prime}\right)\right) \leq 1\right)
\end{aligned}
$$

(True of any plural event that consists of one or more events of taking two pills which each take place within a day.)

This predicate combines with for a month and then with the patient. Under plausible assumptions about the compositional process (see Champollion 2010b, 2016), and omitting the atelicity requirement for clarity, the result is the following:

(92) $\exists e: \operatorname{regular}(\tau(e)) .{ }^{*}$ agent $(e)=$ the.patient $\wedge \operatorname{months}(\tau(e))=1 \wedge$ $e \in{ }^{*} \lambda e^{\prime}\left({ }^{*} \operatorname{take}\left(e^{\prime}\right) \wedge{ }^{*} \operatorname{pill}\left({ }^{*}\right.\right.$ theme $\left.\left(e^{\prime}\right)\right) \wedge \mid{ }^{*}$ theme $\left(e^{\prime}\right) \mid=2$

$$
\left.\wedge \operatorname{days}\left(\tau\left(e^{\prime}\right)\right) \leq 1\right)
$$

(There is a regular plural event that consists of one or more events of taking two pills which each take place within a day. Its agent is the patient, and its runtime measures a month.) 
This formula is verified by a regular plural event that unfolds over the course of a month. The subformula days $\left(\tau\left(e^{\prime}\right)\right) \leq 1$ makes sure that each of the taking-two-pills events $e^{\prime}$ takes place within a day. The pairs of pills covary with the days, even though there is no predicate such as every day explicitly mentioned in the sentence.

While I have not specified the pragmatic mechanism that supplies the value of the granularity parameter of Part in (91), it is instructive to try substituting various predicates for its actual value $\lambda t$.days $(t) \leq 1$. Some potential values are unavailable for various reasons. For example, the predicate Atom is not available in the temporal domain because natural language semantics does not have access to temporal atoms (von Stechow 2009). Other potential values are unavailable because they denote times which are too long (in relation to the interval introduced by the for-adverbial) to satisfy the presuppositions of the for-adverbial (Champollion 2010b, 2017). Finally, predicates that are not salient in the given context will be unavailable because the granularity parameter is taken to be anaphoric (Schwarzschild 1996).

To be sure, sentence (89) conveys more than the literal truth conditions expressed in (92). For example, while (92) is true in a scenario where the patient's daily pill intake is more than two, (89) typically conveys that the pill intake is exactly two. I assume that this is a scalar implicature. When generated in the scope of universal quantifiers and related operators, implicatures raises various theoretical issues; for an overview and discussion, see Schlenker 2016: §22.2. Likewise, (89) implicates that there were no days at which the patient took no pills. This too is arguably an implicature since for some speakers it can be canceled, while inserting every day leads to a contradiction:

(93) John used to take one pill at dinnertime. Then his prescription was doubled, and ...

a. ... he took two pills for a month, but he didn't stick to this regimen every day, so he didn't recover as quickly as he should have.

b. ...\# \#he took two pills every day for a month, but he didn't stick to this regimen every day, so he didn't recover as quickly as he should have.

While judgments are variable, this contrast points to a possible difference between the Part operator and overt distributing expressions like every day. These expressions appear to have stronger truth conditions than Part in 
that they entail that relevant events occur on consecutive days, while Part only implicates this. Accordingly, the truth conditions in (92) do not require consecutivity, only regularity. I come back to the semantics of every day at the end of this section and in Champollion 2016.

The strategy I have adopted here - Theory B plus a distributivity operator anaphoric on context - links the covariation ability of indefinites in the scope of for-adverbials to the presence of a salient temporal predicate. As we have seen, previous classes of theories lack this link. Theory A type accounts place no constraints on covariation, while theory B type accounts prevent it altogether.

The present system does not predict that all quantifiers take wide scope over for-adverbials. We have seen above that bare noun phrases do not take wide scope with respect to for-adverbials, because they denote algebraically closed predicates. This is illustrated in the following minimal pair, repeated here from (69a) and (88):

(94) a. John found fleas (on his dog) for a month. OK b. ??John found a flea (on his dog) for a month. odd out of the blue

As discussed in Section 3, I assume that the denotation of a bare plural like fleas is the algebraic closure of its singular form, essentially one or more fleas. Due to lexical cumulativity, the bare plural in a predicate like find fleas stands in a cumulative-like relation to each of the subintervals over which the for-adverbial quantifies. Sentence (94a) does not entail that any one flea has been found several times, only that there is a plural month-long interval over the course of which one or more fleas were found. This is entailed by the following representation of the denotation of (94a), where fleas is interpreted in situ as a predicate that applies to the theme of the verb:

(95) 『John found fleas for a month $\rrbracket$

$=\exists e: \operatorname{regular}(\tau(e)) \wedge \operatorname{atelic}_{e}\left(\lambda e^{\prime}\left[{ }^{*}\right.\right.$ find $\left(e^{\prime}\right) \wedge{ }^{*}$ flea $\left({ }^{*}\right.$ theme $\left.\left.\left.\left(e^{\prime}\right)\right)\right]\right)$.

$[* \operatorname{agent}(e)=j \wedge *$ find $(e) \wedge *$ flea $(* \operatorname{theme}(e)) \wedge \operatorname{months}(\tau(e))=1]$ (Defined if and only if find fleas is atelic. If defined, true if and only if there is a regular finding event whose theme is a set of fleas, whose agent is John, and whose runtime measures one month.)

The definedness condition of this sentence is fulfilled since find fleas is atelic by most definitions of atelicity (Dowty 1979, Krifka 1998, Champollion 201ob, 2017). Given lexical cumulativity, any event in virtue of which (94a) is true can 
consist of several individual findings. No distributivity operator is needed. This observation is parallel to the argument about meaning postulates in Lasersohn 1989. I discussed this argument in Section 3 in connection with sentences like (17) and (22), repeated here as (96a) and (96b):

(96) a. Rodgers, Hammerstein, and Hart wrote musicals. nonatomic

b. Rodgers, Hammerstein, and Hart wrote a musical. "nonatomic

The system presented here explains the contrast in (96) in the same way as the contrast in (94). In both cases, lexical cumulativity causes the sentence with the bare plural object to exhibit nonatomic lexical distributivity. And in both cases, the sentence with the singular indefinite object does not exhibit nonatomic phrasal distributivity because the lack of supporting context means that the nonatomic distributivity operator Part is not available.

The idea that covariation of singular indefinites is due to the insertion of a covert operator finds additional support in the observation that covarying singular indefinites take extra time to process compared with bare plurals, as discussed in Deo \& Piñango 2011. Reading time increases at the for-adverbial in (97a) compared with (97b) in self-paced reading tests conducted by Todorova et al. (2000). The indefinite in (97a) is able to covary, that is, it involves reference to more than one large check.

(97) a. Even though Howard sent a large check to his daughter for many years, she refused to accept his money.

b. Even though Howard sent large checks to his daughter for many years, she refused to accept his money.

On the view presented here, example (97a) involves the covert presence of a Part operator but example (97b) does not. This kind of contrast can be explained if we assume that the retrieval of an antecedent for the anaphoric variable $C$ in the Part operator leads to a higher processing load. I take examples like (97a) to show that anaphoricity is built into the distributivity operator rather than into the for-adverbial, contrary to Deo \& Piñango (2011).

I have not yet explained why overt interveners like every day can cause singular indefinites in the scope of for-adverbials to involve reference to multiple entities, as in these examples, repeated here from (71):

(98) a. John found a flea on his dog every day for a month.

b. Jim hit a golf ball into the lake every five minutes for an hour. 
The answer is simple: it is the overt universal quantifier in these sentences that causes indefinites in its scope to covary with it, and not the for-adverbial. (The indefinite can in turn escape the scope of the universal quantifier by taking scope above the sentence; the resulting reading is plausible in (98b) but not in (98a).)

This universal quantifier plays a similar role to the Part operator in (86). For this reason, and for other reasons discussed in Champollion 2016, I propose to analyze every day analogously to that operator, with the following modifications (and the analysis of every five minutes is similar). First, every day hardwires the granularity parameter to the value $\lambda t$ [days $(t) \leq 1$ ] instead of retrieving it anaphorically from context. Second, as we have seen, every day entails that no relevant day is left out, while the Part operator merely implicates this.

The output of every day must satisfy the atelicity requirement imposed by the for-adverbial. This would not be the case, for example, if we let every day universally quantify over a fixed set of days. The underlined formula in (99) ensures that every day in some consecutive span is the runtime of a relevant event, and it satisfies the atelicity requirement by existentially quantifying over that span rather than fixing it.

$$
\begin{aligned}
& \llbracket \text { every day } \stackrel{\text { def }}{=} \lambda V \lambda e\left[e \in{ }^{*} \lambda e^{\prime}\left(V\left(e^{\prime}\right) \wedge \operatorname{days}\left(\tau\left(e^{\prime}\right)\right) \leq 1\right) \wedge\right. \\
& \quad \exists t \text {.continuous }(t) \wedge \\
& \left.\forall t^{\prime} .\left[t^{\prime} \leq t \wedge \text { days }\left(t^{\prime}\right)=1 \rightarrow \exists e^{\prime} . e^{\prime} \leq e \wedge V\left(e^{\prime}\right) \wedge \tau\left(e^{\prime}\right) \leq t^{\prime}\right]\right]
\end{aligned}
$$

(Takes an event predicate $V$ and returns a predicate that holds of any event $e$ which consists entirely of events that are in $V$ and whose runtimes are at most one day long, in such a way that no day in a consecutive span of days is left out.)

While this entry induces covariation in indefinites as desired, it is only a sketch and raises avenues for further research. For example, one could try to derive the requirement that days be consecutive from general properties of domain restriction (see e.g., Stanley \& Szabó 2000, Schwarz 2009: Chapter 3). Those properties might perhaps also capture the fact that every day quantifies over a set that is maximal in some salient way but that can be bounded by temporal adverbials and tense. For example, in (98a), every day quantifies over some set of past days that are all contained within the same month. A proper account of every day must be integrated into an account of temporal dependencies (Pratt \& Francez 2001, von Stechow 2002, Champollion 2011b). Furthermore, making (99) compositional would need more work, whether 
we build on classical accounts of every or on the event-based treatment in Champollion 2016. Either way, one would need to determine the source of the consecutivity requirement of every day, which has no obvious counterpart in ordinary cases of universal quantification such as every dog. The behavior of pluractional adverbials like day after day, dog after dog, etc., might be relevant here (Beck \& von Stechow 2007).

To sum up this section, there are two kinds of theories of the scopal effects of for-adverbials on indefinites: those that predict indefinites can always covary, and those that predict that they never do. The first kind of theory overgenerates and the second kind undergenerates. I have solved this puzzle by transferring the cover-based approach to distributivity in Schwarzschild 1996 into the temporal domain. Adopting Neo-Davidsonian event semantics with its parallel treatment of arguments and adjuncts made this transfer easy. On the resulting account, it is not the for-adverbials that induce covariation but contextually dependent distributivity operators. These operators are similar in this respect to overt quantifiers like every day, which induce covariation when they intervene between the for-adverbial and the indefinite.

\section{Conclusion}

This paper has presented a theory of covert distributivity in natural language. Covert phrasal distributivity has been at the center of a long debate as to whether it always involves distribution over atoms (Lasersohn 1989, Winter 2001) or whether it can also involve distribution over pragmatically salient nonatomic entities (Gillon 1990, Champollion 2010b). The framework developed here combines ideas from algebraic semantics (Link 1983) and Neo-Davidsonian event semantics (Parsons 1990), which exposes thematic roles to the compositional process. I have suggested that distributivity operators are parametric on thematic roles and, in certain cases, on salient predicates such as covers. I have suggested two divisions of labor, one between meaning postulates and distributivity operators and the other one between semantics and pragmatics, that account for the limited availability of nonatomic distributivity. This provides an advantage over theories in which nonatomic distributivity is freely available, those in which it is not available at all, and those where its availability does not depend on the difference between lexical and phrasal distributivity. I have extended this account to the temporal domain, where it predicts the limited availability of indefinites 
to covary in the scope of for-adverbials. This provides an advantage over theories that predict such indefinites to always covary and those that predict them to never covary. I have reformulated the atomic distributivity operator D of Link 1987 and the cover-based nonatomic distributivity operator Part of Schwarzschild 1996 in algebraic event semantics in a way that makes the sum event available for further modification by arguments and adjuncts, which was not the case in previous implementations.

I have integrated these operators into the stratified reference framework, in which distributivity has two parameters. The first parameter specifies the dimension or thematic role that is targeted, which may also be runtime. The second parameter specifies the granularity or size of the distributed entities. Stratified reference allows us to connect the present theory of distributivity more broadly to aspect and measurement (Champollion 2010b).

I have empirically distinguished lexical and phrasal distributivity. Following earlier work, I have suggested that lexical distributivity should be modeled by the lexical cumulativity assumption (Lasersohn 1989, Kratzer 2007). In keeping with the observation that nonatomic phrasal distributivity exists but requires supporting context to surface, I have suggested that this fact motivates the possibility of a nonatomic granularity parameter setting for the distributivity operator. I have assumed that this happens so rarely because the operator is anaphoric on its context with respect to this parameter (Schwarzschild 1996). Examples like (23), repeated as (10oa), have a nonatomic reading because there is a salient nonatomic level of granularity, while examples like (24), repeated as (100b), do not have such a reading. I have extended this parallel to the temporal domain, where I have argued that a salient level of granularity provides a way for the indefinite in (89), repeated as (101a), to involve reference to different sets of two pills, while such a reading is not present in (101b).

(100) a. The shoes cost fifty dollars (i.e., per pair).

b. The suitcases weigh fifty pounds.

(101) a. The patient took two pills for a month (i.e., per day).

b. ??John found a flea for a month (i.e., per day).

This concludes the first of two papers about distributivity in algebraic event semantics. The second paper, Champollion 2016, turns to overt distributivity. Across languages, overt phrasal distributivity is often expressed via adverbials and adnominals, such as English each and German jeweils (Zim- 
mermann 2002). Such items differ with respect to whether they are restricted to distribution over individuals mentioned in the same sentence (like D), or whether they can also distribute over pragmatically salient occasions that need not have been explicitly mentioned (like Part). This parallel to the D and Part operators is central to Champollion 2016.

\section{References}

Barker, Chris. 2010. Free choice permission as resource-sensitive reasoning. Semantics and Pragmatics 3(10). 1-38. https://doi.org/10.3765/sp.3.10.

Bayer, Samuel L. 1997. Confessions of a lapsed Neo-Davidsonian: Events and arguments in compositional semantics. New York, NY: Garland. https: //doi.org/10.4324/9780203055106.

Beck, Sigrid \& Uli Sauerland. 2000. Cumulation is needed: A reply to Winter (2000). Natural Language Semantics 8(4). 349-371. https://doi.org/10. 1023/a:1011240827230.

Beck, Sigrid \& Arnim von Stechow. 2007. Pluractional adverbials. Journal of Semantics 24(3). 215-254. https://doi.org/10.1093/jos/ffmoo3.

Blaheta, Don. 2003. Binominal each: Evidence for a modified type system. Providence, RI: Brown University MA thesis. http://citeseerx.ist.psu.edu/ viewdoc/summary?doi=10.1.1.10.7455.

Brasoveanu, Adrian. 2013. Modified numerals as post-suppositions. Journal of Semantics 30(2). 155-209. https://doi.org/10.1093/jos/ffsoo3.

Brisson, Christine. 1998. Distributivity, maximality, and floating quantifiers. New Brunswick, NJ: Rutgers University dissertation. http://ling.rutgers. edu/images/10.1.1.121.4641.pdf.

Brisson, Christine. 2003. Plurals, all, and the nonuniformity of collective predication. Linguistics and Philosophy 26(2). 129-184. https://doi.org/10. 1023/a:1022771705575.

Carlson, Gregory N. 1977. Reference to kinds in English. Amherst, MA: University of Massachusetts dissertation. http://semanticsarchive.net/Archive/ jk3NzRlY.

Carlson, Gregory N. 1984. Thematic roles and their role in semantic interpretation. Linguistics 22(3). 259-280. https://doi.org/10.1515/ling.1984.22.3.259.

Carlson, Gregory N. 1998. Thematic roles and the individuation of events. In Susan Rothstein (ed.), Events and grammar, 35-51. Dordrecht, Netherlands: Kluwer. https://doi.org/10.1007/978-94-011-3969-4_3. 
Covert distributivity in algebraic event semantics

Champollion, Lucas. to appear. Distributivity, collectivity and cumulativity. In Lisa Matthewson, Cécile Meier, Hotze Rullmann \& Thomas Ede Zimmermann (eds.), Wiley's companion to semantics. Hoboken, NJ: Wiley. http://ling.auf.net/lingbuzz/oo2133.

Champollion, Lucas. 2010a. Cumulative readings of every do not provide evidence for events and thematic roles. Logic, Language and Meaning: 17th Amsterdam Colloquium. 213-222. https://doi.org/10.1007/978-3-64214287-1_22.

Champollion, Lucas. 2010b. Parts of a whole: Distributivity as a bridge between aspect and measurement. Philadelphia, PA: University of Pennsylvania dissertation. http://repository.upenn.edu/edissertations/958/.

Champollion, Lucas. 2011a. Quantification and negation in event semantics. The Baltic International Yearbook of Cognition, Logic and Communication 6. 1-23. https://doi.org/10.4148/biyclc.v6io.1563.

Champollion, Lucas. 2011b. Temporal prepositional phrases and implicit variables. Ms. University of Tübingen. http://www.champollion.com/ temporal-pps-and-implicit-variables.pdf.

Champollion, Lucas. 2012. Each vs. jeweils: A cover-based view on distance distributivity. Logic, Language and Meaning: 18th Amsterdam Colloquium. 251-26o. https://doi.org/10.1007/978-3-642-31482-7_26.

Champollion, Lucas. 2013. The scope and processing of for-adverbials: A reply to Deo and Piñango. Semantics and Linguistic Theory (SALT) 23. 432-452. https://doi.org/10.3765/salt.v23io.2680.

Champollion, Lucas. 2014. Reply to Roger Schwarzschild on event semantics. Ms. New York University. http://ling.auf.net/lingbuzz/o02165.

Champollion, Lucas. 2015a. Refining stratified reference. Theoretical Linguistics 41(3-4). 223-240. https://doi.org/10.1515/tl-2015-0015.

Champollion, Lucas. 2015b. Stratified reference: The common core of distributivity, aspect, and measurement. Theoretical Linguistics 41(3-4). 109-149. https://doi.org/10.1515/tl-2015-0oo8.

Champollion, Lucas. 2015c. The interaction of compositional semantics and event semantics. Linguistics and Philosophy 38(1). 31-66. https://doi.org/ 10.1007/s10988-014-9162-8.

Champollion, Lucas. 2016. Overt distributivity in algebraic event semantics. Semantics and Pragmatics 9(16). 1-65. https://doi.org/10.3765/sp.9.16.

Champollion, Lucas. 2017. Parts of a whole: Distributivity as a bridge between aspect and measurement. 1st edn. Vol. 66 (Oxford Studies in Theoretical 
Linguistics). Oxford, UK: Oxford University Press. https://doi.org/10. 1093/oso/9780198755128.001.0001.

Champollion, Lucas \& Manfred Krifka. 2016. Mereology. In Maria Aloni \& Paul Dekker (eds.), Cambridge handbook of formal semantics (Cambridge Handbooks in Language and Linguistics), chap. 13, 369-388. Cambridge, UK: Cambridge University Press. https://doi.org/10.1017/CBO9781139236157. O14.

Cheng, Chung-Ying. 1973. Comments on Moravcsik's paper. In Jaakko Hintikka, Julius Moravcsik \& Patrick Suppes (eds.), Approaches to natural language: 1970 Stanford workshop on grammar and semantics, 286-288. Dordrecht, Netherlands: Reidel. https://doi.org/10.1007/978-94-0102506-5_14.

Davidson, Donald. 1967. The logical form of action sentences. In Nicholas Rescher (ed.), The logic of decision and action, 81-95. Pittsburgh, PA: University of Pittsburgh Press. https://doi.org/10.1093/0199246270.003. ooo6.

Deo, Ashwini Sharad. 2009. Unifying the imperfective and the progressive: Partitions as quantificational domains. Linguistics and Philosophy 32(5). 475-521. https://doi.org/10.1007/s10988-010-9068-z.

Deo, Ashwini Sharad \& Maria Mercedes Piñango. 2011. Quantification and context in measure adverbs. Semantics and Linguistic Theory (SALT) 21. 295-312. https://doi.org/10.3765/salt.v21io.2614.

van der Does, Jaap. 1993. Sums and quantifiers. Linguistics and Philosophy 16(5). 509-550. https://doi.org/10.1007/BFoog86210.

van der Does, Jaap \& Henk J. Verkuyl. 1996. Quantification and predication. In Kees van Deemter \& Stanley Peters (eds.), Semantic ambiguity and underspecification, 27-54. Stanford, CA: CSLI Publications. http://citeseerx. ist.psu.edu/viewdoc/summary?doi=10.1.1.37.8829.

Dotlačil, Jakub. 2010. Anaphora and distributivity: A study of same, different, reciprocals and others. Utrecht, Netherlands: Utrecht University dissertation. https://dspace.library.uu.nl/handle/1874/44918.

Dowty, David R. 1979. Word meaning and Montague grammar: The semantics of verbs and times in generative semantics and in Montague's PTQ. Dordrecht, Netherlands: Reidel. https://doi.org/10.1007/978-94-009-9473-7. Dowty, David R. 1987. Collective predicates, distributive predicates, and all. In Ann Miller \& Zheng-sheng Zhang (eds.), Eastern States Conference on Linguistics (ESCOL) 3, 97-115. Columbus, OH: Ohio State University. 
Covert distributivity in algebraic event semantics

Eckardt, Regine. 1998. Adverbs, events, and other things. Vol. 379 (Linguistische Arbeiten). Tübingen, Germany: Niemeyer. https://doi.org/10.1515/ 9783110913781.

Ferreira, Marcelo. 2005. Event quantification and plurality. Cambridge, MA: Massachusetts Institute of Technology dissertation. http://hdl.handle. net/1721.1/33697.

Fine, Kit. 2012. Counterfactuals without possible worlds. The Journal of Philosophy 109(3). 221-246. https://doi.org/10.5840/jphil201210938.

van Geenhoven, Veerle. 2004. For-adverbials, frequentative aspect, and pluractionality. Natural Language Semantics 12(2). 135-190. https://doi.org/ 10.1023/b:nals.ooooo31389.36427.af.

van Geenhoven, Veerle. 2005. Atelicity, pluractionality and adverbial quantification. In Henk J. Verkuyl, Henriëtte de Swart \& Angeliek van Hout (eds.), Perspectives on aspect, vol. 32 (Studies in theoretical psycholinguistics), 107-124. Berlin, Germany: Springer. https://doi.org/10.1007/1-4020-32323_6.

Gillon, Brendan S. 1987. The readings of plural noun phrases in English. Linguistics and Philosophy 10(2). 199-219. https://doi.org/10.1007/ bfoo 584318.

Gillon, Brendan S. 1990. Plural noun phrases and their readings: A reply to Lasersohn. Linguistics and Philosophy 13(4). 477-485. https://doi.org/10. 1007/bfoo630751.

Groenendijk, Jeroen, Theo Janssen \& Martin Stokhof (eds.). 1984. Truth, interpretation and information: 3rd Amsterdam Colloquium. Dordrecht, Netherlands: Foris. https://doi.org/10.1515/9783110867602.

Harley, Heidi. 2012. Semantics in distributed morphology. In Claudia Maienborn, Klaus von Heusinger \& Paul Portner (eds.), Semantics: An international handbook of natural language meaning, vol. 3, 2151-2172. de Gruyter. https://doi.org/10.1515/9783110253382.2151.

Heim, Irene. 1994. Plurals. Ms. Massachusetts Institute of Technology. http: //www.sfs.uni-tuebingen.de/ astechow/Lehre/SSo8/Heim_Plurals\%2O' 94.pdf.

Heim, Irene \& Angelika Kratzer. 1998. Semantics in Generative Grammar. Oxford, UK: Blackwell Publishing.

Hoeksema, Jack. 1983. Plurality and conjunction. In Alice ter Meulen (ed.), Studies in modeltheoretic semantics, 63-83. Dordrecht, Netherlands: Foris. Hovda, Peter. 2009. What is classical mereology? Journal of Philosophical Logic 38(1). 55-82. https://doi.org/10.1007/s10992-008-9092-4. 
Kennedy, Christopher. 2007. Vagueness and grammar: The semantics of relative and absolute gradable adjectives. Linguistics and Philosophy 30(1). 1-45. https://doi.org/10.1007/s10988-006-9008-o.

Kratzer, Angelika. 1996. Severing the external argument from its verb. In Johan Rooryck \& Laurie Zaring (eds.), Phrase structure and the lexicon, 109-137. Dordrecht, Netherlands: Kluwer. https://doi.org/10.1007/97894-015-8617-7-5.

Kratzer, Angelika. 2003. The event argument and the semantics of verbs, chapter 3. Ms. University of Massachusetts, Amherst. http://semanticsarchive.net/Archive/GU1NWM4Z/.

Kratzer, Angelika. 2007. On the plurality of verbs. In Johannes Dölling, Tatjana Heyde-Zybatow \& Martin Schäfer (eds.), Event structures in linguistic form and interpretation, 269-300. Berlin, Germany: de Gruyter. https://doi.org/ 10.1515/9783110925449.269.

Kratzer, Angelika. 2016. Situations in natural language semantics. In Edward N. Zalta (ed.), The Stanford encyclopedia of philosophy, Spring 2016. Stanford, CA. https://plato.stanford.edu/archives/spr2016/entries/situationssemantics/.

Krifka, Manfred. 1989a. Nominal reference, temporal constitution and quantification in event semantics. In Renate Bartsch, Johan van Benthem \& Peter van Emde Boas (eds.), Semantics and contextual expression, 75-115. Dordrecht, Netherlands: Foris. http://amor.cms.hu-berlin.de/ h2816i3x/ Publications/Krifka\%201989\%20Nominal\%2oReference.pdf.

Krifka, Manfred. 1989b. Nominalreferenz und Zeitkonstitution: Zur Semantik von Massentermen, Pluraltermen und Aspektklassen. Munich, Germany: Wilhelm Fink. http://amor.cms.hu-berlin.de/ h2816i3x/Publications/ Krifka_1989_Nominalreferenz_Zeitkonstitution.PDF.

Krifka, Manfred. 1992. Thematic relations as links between nominal reference and temporal constitution. In Ivan A. Sag \& Anna Szabolcsi (eds.), Lexical matters, 29-53. Stanford, CA: CSLI Publications. http://amor . cms.hu-berlin.de/ h2816i3x/Publications/Krifka\%201992\%20Thematic\% 20Relations.PDF.

Krifka, Manfred. 1998. The origins of telicity. In Susan Rothstein (ed.), Events and grammar, vol. 70 (Studies in linguistics and philosophy), 197-235. Dordrecht, Netherlands: Kluwer. https://doi.org/10.1007/978-94-0113969-4-9.

Krifka, Manfred. 1999. At least some determiners aren't determiners. In Ken Turner (ed.), The semantics/pragmatics interface from different points of 
Covert distributivity in algebraic event semantics

view, 257-291. Amsterdam, Netherlands: Elsevier. http://amor.cms.huberlin.de/ h2816i3x/Publications/ATLEASTSOME.pdf.

Landman, Fred. 1989. Groups, I. Linguistics and Philosophy 12(5). 559-605. https://doi.org/10.1007/bfoo627774.

Landman, Fred. 1996. Plurality. In Shalom Lappin (ed.), Handbook of contemporary semantic theory, 425-457. Oxford, UK: Blackwell Publishing. https://doi.org/10.1111/b.9780631207498.1997.00019.x.

Landman, Fred. 200o. Events and plurality: The Jerusalem lectures. Dordrecht, Netherlands: Kluwer. https://doi.org/10.1007/978-94-011-4359-2.

Landman, Fred \& Susan Rothstein. 2010. Incremental homogeneity in the semantics of aspectual for-phrases. In Malka Rappaport Hovav, Ivi Sichel \& Edit Doron (eds.), Syntax, lexical semantics and event structure, 229-251. Amsterdam, Netherlands: John Benjamins. https://doi.org/10.1093/ acprof:0so/9780199544325.003.0011.

Landman, Fred \& Susan Rothstein. 2012a. The felicity of aspectual forphrases - Part 1: Homogeneity. Language and Linguistics Compass 6(2). 85-96. https://doi.org/10.1002/lnc3.324.

Landman, Fred \& Susan Rothstein. 2012b. The felicity of aspectual forphrases - Part 2: Incremental homogeneity. Language and Linguistics Compass 6(2). 97-112. https://doi.org/10.1002/lnc3.323.

Lasersohn, Peter. 1988. A semantics for groups and events. Columbus, OH: Ohio State University dissertation. http://semanticsarchive.net/Archive/ $\mathrm{zQ} 2 \mathrm{ODQxN} /$.

Lasersohn, Peter. 1989. On the readings of plural noun phrases. Linguistic Inquiry 20(1). 130-134. http://www.jstor.org/stable/4178619.

Lasersohn, Peter. 1992. Generalized conjunction and temporal modification. Linguistics and Philosophy 15(4).381-410. https://doi.org/10.1007/ bfoo627682.

Lasersohn, Peter. 1995. Plurality, conjunction and events. Dordrecht, Netherlands: Kluwer. https://doi.org/10.1007/978-94-015-8581-1.

Lasersohn, Peter. 1998. Generalized distributivity operators. Linguistics and Philosophy 21(1). 83-93. https://doi.org/10.1023/a:1005317815339.

LaTerza, Chris. 2014. Distributivity and plural anaphora. College Park, MD: University of Maryland dissertation. http://hdl.handle.net/1903/15826.

Link, Godehard. 1983. The logical analysis of plurals and mass terms: A lattice-theoretical approach. In Reiner Bäuerle, Christoph Schwarze \& Arnim von Stechow (eds.), Meaning, use and interpretation of language, 
303-323. Reprinted in Link 1998, Chapter 1. Berlin, Germany: de Gruyter. https://doi.org/10.1515/9783110852820.302.

Link, Godehard. 1987. Generalized quantifiers and plurals. In Peter Gärdenfors (ed.), Generalized quantifiers, 151-180. Reprinted in Link 1998, Chapter 4. Berlin, Germany: Springer. https://doi.org/10.1007/978-94-0o9-3381-1_6. Link, Godehard. 1991. Plural. In Arnim von Stechow \& Dieter Wunderlich (eds.), Semantics: An international handbook of contemporary research, 418-440. Reprinted in Link 1998, Chapter 2, translated by the author. Berlin, Germany: de Gruyter.

Link, Godehard. 1997. Ten years of research on plurals - Where do we stand? In Fritz Hamm \& Erhard Hinrichs (eds.), Plurality and quantification, vol. 69 (Studies in Linguistics and Philosophy), 19-54. Reprinted in Link 1998, Chapter 7. Dordrecht, Netherlands: Kluwer. https://doi.org/10.1007/97894-017-2706-8_2.

Link, Godehard. 1998. Algebraic semantics in language and philosophy. Stanford, CA: CSLI Publications.

Malamud, Sophia A. 2006a. (Non)maximality and distributivity: A decision theory approach. Semantics and Linguistic Theory (SALT) 16. 120-137. https://doi.org/10.3765/salt.v16io.2943.

Malamud, Sophia A. 2006b. Semantics and pragmatics of arbitrariness. Philadelphia, PA: University of Pennsylvania dissertation. http://people. brandeis.edu/ smalamud/Malamud-diss-single.pdf.

Malamud, Sophia A. 2012. The meaning of plural definites: A decisiontheoretic approach. Semantics and Pragmatics 5(3). 1-58. https://doi. org/10.3765/sp.5.3.

Moltmann, Friederike. 1991. Measure adverbials. Linguistics and Philosophy 14(6). 629-66o. https://doi.org/10.1007/bfoo631962.

Parsons, Terence. 1990. Events in the semantics of English. Cambridge, MA: MIT Press.

Parsons, Terence. 1995. Thematic relations and arguments. Linguistic Inquiry 26(4). 635-662. http://www.jstor.org/stable/4178917.

Pietroski, Paul M. 2004. Events and semantic architecture. Oxford, UK: Oxford University Press. https://doi.org/10.1093/acprof:oso/9780199244300. 001.0001.

Pietroski, Paul M. 2006. Interpreting concatenation and concatenates. Philosophical Issues 16(1). 221-245. https://doi.org/10.1111/j.1533-6077.2006. ool11.x. 
Covert distributivity in algebraic event semantics

Piñón, Christopher. 1999. A semantics for durative adverbials. In Sinn und Bedeutung 4. Düsseldorf, Germany: University of Düsseldorf. http:// pinon.sdf-eu.org/work/pinon_sda_ho.pdf.

Potts, Christopher. 2008. Interpretive economy, Schelling points, and evolutionary stability. Ms. University of Massachusetts, Amherst. http:// semanticsarchive.net/Archive/jExYWZIN/.

Pratt, Ian \& Nissim Francez. 2001. Temporal prepositions and temporal generalized quantifiers. Linguistics and Philosophy 24(2). 187-255. https: //doi.org/10.1023/a:1005632801858.

Roberts, Craige. 1987. Modal subordination, anaphora, and distributivity. Amherst, MA: University of Massachusetts dissertation. http://scholarworks. umass.edu/dissertations/AAI8710499.

van Rooij, Robert. 2003. Questioning to resolve decision problems. Linguistics and Philosophy 26(6). 727-763. https://doi.org/10.1023/b:ling. oooooo4548.98658.8f.

Rothstein, Susan. 2010. Counting and the mass/count distinction. Journal of Semantics 27(3). 343-397. https://doi.org/10.1093/jos/ffqoo7.

Sauerland, Uli, Jan Anderssen \& Kazuko Yatsushiro. 2005. The plural is semantically unmarked. In Stephan Kepser \& Marga Reis (eds.), Linguistic evidence: Empirical, theoretical and computational perspectives, 413-434. Berlin, Germany: de Gruyter. https://doi.org/10.1515/9783110197549.413. Scha, Remko. 1981. Distributive, collective and cumulative quantification. In Jeroen Groenendijk, Theo Janssen \& Martin Stokhof (eds.), Formal methods in the study of language, 483-512. Reprinted in Groenendijk, Janssen \& Stokhof 1984. Amsterdam, Netherlands: Mathematical Center Tracts. https://doi.org/10.1515/9783110867602.131.

Schein, Barry. 1986. Event logic and the interpretation of plurals. Cambridge, MA: Massachusetts Institute of Technology dissertation. http://hdl . handle.net/1721.1/15107.

Schein, Barry. 1993. Plurals and events. Cambridge, MA: MIT Press.

Schlenker, Philippe. 2016. The semantics-pragmatics interface. In Maria Aloni \& Paul Dekker (eds.), Cambridge handbook of formal semantics (Cambridge Handbooks in Language and Linguistics), chap. 22, 664-727. Cambridge, UK: Cambridge University Press. https://doi.org/10.1017/ CBO9781139236157.023.

Schwarz, Florian. 2009. Two types of definites in natural language. Amherst, MA: University of Massachusetts dissertation. http://scholarworks.umass. edu/open_access_dissertations/122. 
Schwarzschild, Roger. 1996. Pluralities. Vol. 61 (Studies in Linguistics and Philosophy). Dordrecht, Netherlands: Kluwer. https://doi.org/10.1007/ 978-94-017-2704-4.

Schwarzschild, Roger. 2014. Distributivity, negation and quantification in event semantics: Recent work by L. Champollion. Ms. Massachusetts Institute of Technology. http://web.mit.edu/schild/www/papers/public_ html/champ.pdf.

Schwarzschild, Roger. 2015. Partitives and duratives. Theoretical Linguistics 41(3-4). https://doi.org/10.1515/tl-2015-0013.

Spector, Benjamin. 2007. Aspects of the pragmatics of plural morphology: On higher-order implicatures. In Uli Sauerland \& Penka Stateva (eds.), Presupposition and implicature in compositional semantics, 243-281. London, UK: Palgrave. https://doi.org/10.1057/9780230210752_9.

Stanley, Jason \& Zoltán Gendler Szabó. 200o. On quantifier domain restriction. Mind and Language 15(2-3). 219-261. https://doi.org/10.1111/14680017.00130.

von Stechow, Arnim. 2002. Temporal prepositional phrases with quantifiers: Some additions to Pratt and Francez (2001). Linguistics and Philosophy 25(5-6). 755-800. https://doi.org/10.1023/a:1020872017811.

von Stechow, Arnim. 2009. Tenses in compositional semantics. In Wolfgang Klein \& Ping Li (eds.), The expression of time, 129-166. Berlin, Germany: de Gruyter. https://doi.org/10.1515/9783110199031.129.

Sternefeld, Wolfgang. 1998. Reciprocity and cumulative predication. Natural Language Semantics 6(3). 303-337. https://doi.org/10.1023/a: 1008352502939 .

Tarski, Alfred. 1935. Zur Grundlegung der Boole'schen Algebra I. Fundamenta Mathematicae 24. Translated to English as Tarski 1956, 177-198. https: //eudml.org/doc/212745.

Tarski, Alfred. 1956. On the foundations of the Boolean algebra. In Joseph Henry Woodger (ed.), Logics, semantics, metamathematics. Papers from 1923 to 1938, 320-341. Translation of Tarski 1935. Oxford, UK: Clarendon. Taylor, Barry. 1985. Modes of occurrence. Oxford, UK: Basil Blackwell.

Todorova, Marina, Karen Straub, William Badecker \& Robert Frank. 2000. Aspectual coercion and the online computation of sentential aspect. In Lila R. Gleitman \& Aravind K. Joshi (eds.), 22nd Annual Conference of the Cognitive Science Society, 3-8. http://citeseerx.ist.psu.edu/viewdoc/ summary?doi=10.1.1.23.8886. 
Covert distributivity in algebraic event semantics

Vendler, Zeno. 1957. Verbs and times. The Philosophical Review 66(2). 14316o. https://doi.org/10.2307/2182371.

Verkuyl, Henk J. 1972. On the compositional nature of the aspects. Dordrecht, Netherlands: Reidel. https://doi.org/10.1007/978-94-017-2478-4.

Verkuyl, Henk J. \& Jaap van der Does. 1991. The semantics of plural noun phrases. Vol. LP-91-O7 (ITLI prepublication series for logic, semantics and philosophy of language). Amsterdam, Netherlands: University of Amsterdam. https://www.illc.uva.nl/Research/Publications/Reports/LP1991-07.text.pdf.

Vlach, Frank. 1993. Temporal adverbials, tenses and the Perfect. Linguistics and Philosophy 16(3). 231-283. https://doi.org/10.1007/bfoog85970.

Williams, Alexander. 2009. Themes, cumulativity, and resultatives: Comments on Kratzer 2003. Linguistic Inquiry 40(4). 686-700. https://doi.org/10. 1162/ling.2009.40.4.686.

Winter, Yoad. 1997. Choice functions and the scopal semantics of indefinites. Linguistics and Philosophy 20(4). 399-467. https://doi.org/10.1023/a: 1005354323136.

Winter, Yoad. 2001. Flexibility principles in Boolean semantics: The interpretation of coordination, plurality, and scope in natural language. Cambridge, MA: MIT Press.

Zimmermann, Malte. 2002. Boys buying two sausages each: On the syntax and semantics of distance-distributivity. Amsterdam, Netherlands: University of Amsterdam dissertation. http://hdl.handle.net/11245/1.194584.

Zucchi, Sandro \& Michael White. 2001. Twigs, sequences and the temporal constitution of predicates. Linguistics and Philosophy 24(2). 223-270. https: //doi.org/10.1023/a:1005690022190.

Zweig, Eytan. 2008. Dependent plurals and plural meaning. New York, NY: New York University dissertation. http://semanticsarchive.net/Archive/ GJhMzhhZ/.

Zweig, Eytan. 2009. Number-neutral bare plurals and the multiplicity implicature. Linguistics and Philosophy 32(4). 353-407. https://doi.org/10.1007/ s10988-0o9-9064-3.

Lucas Champollion

New York University

10 Washington Place

New York, NY 10003, USA

champollion@nyu.edu 